University of Massachusetts Amherst

ScholarWorks@UMass Amherst

Doctoral Dissertations 1896 - February 2014

$1-1-1975$

\title{
The role of the hippocampus in blocking and conditioned inhibition of the rabbit's nictitating membrane response.
}

Paul R. Solomon

University of Massachusetts Amherst

Follow this and additional works at: https://scholarworks.umass.edu/dissertations_1

\section{Recommended Citation}

Solomon, Paul R., "The role of the hippocampus in blocking and conditioned inhibition of the rabbit's nictitating membrane response." (1975). Doctoral Dissertations 1896 - February 2014. 1592. https://doi.org/10.7275/dqww-qc23 https://scholarworks.umass.edu/dissertations_1/1592

This Open Access Dissertation is brought to you for free and open access by ScholarWorks@UMass Amherst. It has been accepted for inclusion in Doctoral Dissertations 1896 - February 2014 by an authorized administrator of ScholarWorks@UMass Amherst. For more information, please contact scholarworks@library.umass.edu. 


\section{4}


THE ROLE OF THE HIPPOCAMPUS IN BLOCKING AND CONDITIONED INHIBITION OF THE RABBIT'S NICTITATING MEMBRANE RESPONSE

A Dissertation Presented

by

Paul R. Solomon

Submitted to the Graduate School of the University of Massachusetts in partial fulfillment of the requirements for the degree of DOCTOR OF PHILOSOPHY

$$
\text { July, } 1975
$$

Psychology 
THE ROLE OF THE HIPPOCAMPUS IN BLOCKING AND CONDITIONED INHIBITION OF THE RABBIT'S NICTITATING MEMBRANE RESPONSE

\author{
A Dissertation \\ by \\ Paul R. Solomon
}

Approved as to style and content by:
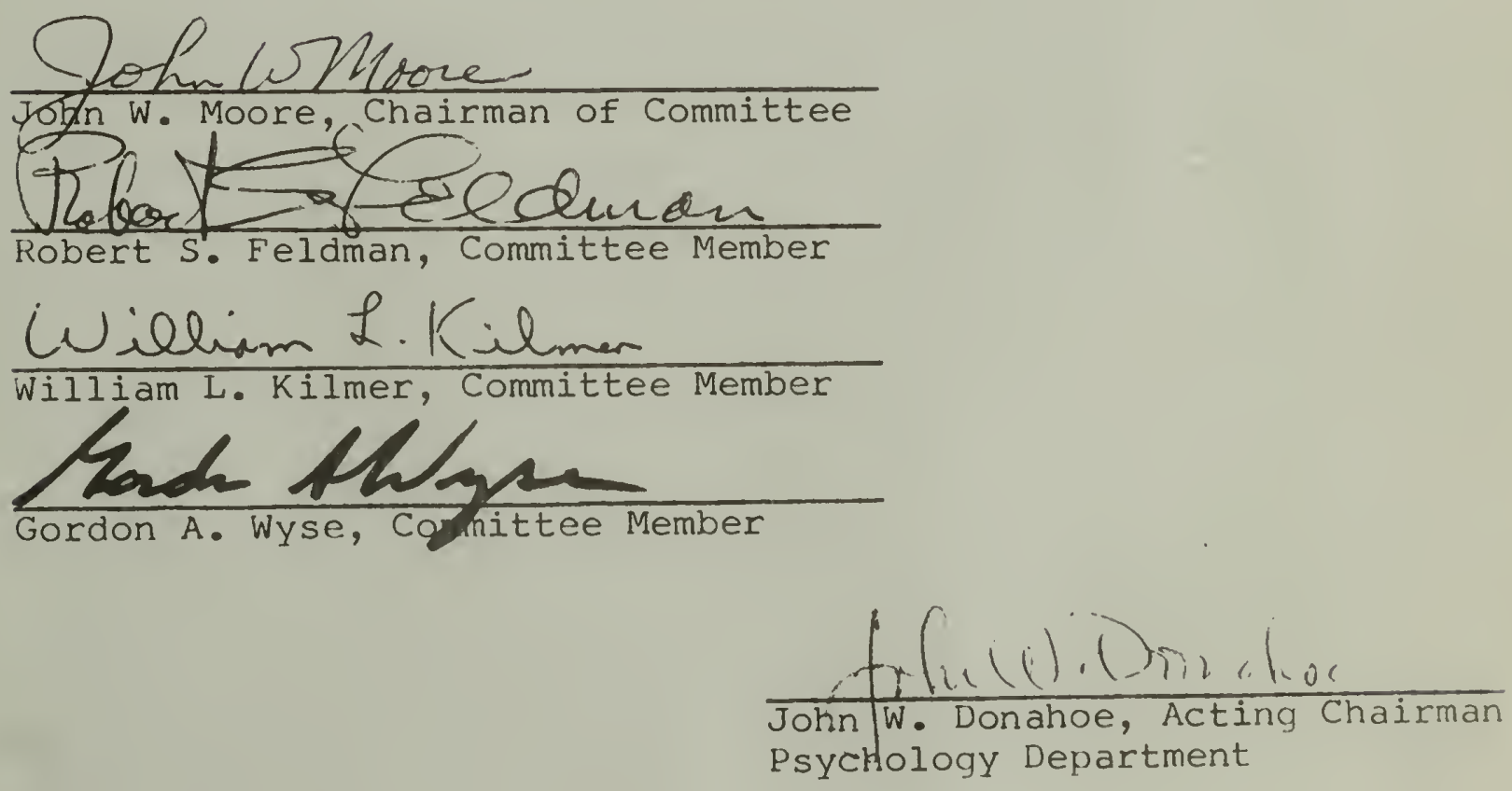

June, 1975 


\section{Abstract}

Bilateral aspiration of the dorsal hippocampus produced a disruption of blocking of the rabbit's nictitating membrane response in Kamin's two-stage paradigm (Experiment 1), but had no effect on the formation of a Pavlovian conditioned inhibitor, (Experiment 2).

The results of Experiment 1 indicated that cortical, lesioned and normal animals given conditioning to a light plus tone CS, gave CRS to both the light and tone during nonreinforced presentations of each (test phase). If, however, compound conditioning was preceded by tone acquisition, only the tone elicited a CR during testing; that is, blocking was observed. In hippocampal lesioned rabbits, however, CRs were given to both the light and tone during testing whether or not compound conditioning was preceded by tone acquisition.

The data from Experiment 2 showed that hippocampal lesioned rabbits could discriminate as well as cortical, lesioned or normal animals between a light (CS+) and a light plus tone (CS-). In addition, when the inhibitory tone was subsequently paired with the UCS in retardation testing, animals in all three lesion conditions acquired the $\mathrm{CR}$ at the same rate. Thus, it appears that hippocampal lesions do not disrupt the conditioned inhibition process. 
The results of these experiments were taken as support for the view that the hippocampus is responsible for tuning out motivationally nonsignificant stimuli. 


\section{Acknowledgements}

I would like to thank the members of my committee, Dr. Robert S. Feldman and Dr. Gordon S. Wyse for teaching me the fundamentals of the neurosciences, and Dr. William L. Kilmer for sharing his provocative thoughts on the hippocampus. A sincere note of gratitude is due my advisor and teacher, Dr. John W. Moore, not so much for telling me the answers, but for teaching me how to ask the questions. I would also like to express a special note of thanks to Dr. David L. Morse. Although he had little to do with this dissertation, he has been an important part of both my undergraduate and graduate education.

A note of thanks is due to my parents who instilled in me, at an early age, a desire for knowledge.

Lastly, a mere thank you is hardly sufficient to acknowledge the contribution of my wife Suellen. Her love and support have made this endeavor not only possible, but pleasant. 
Table of Contents

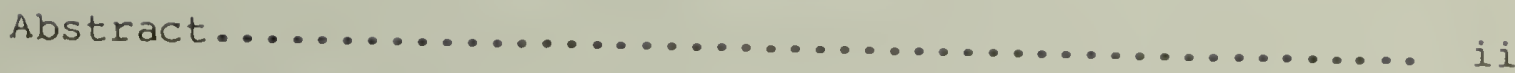

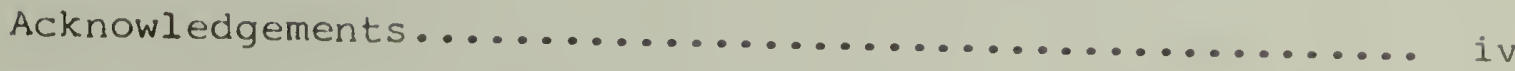

List of Figures............................. vi

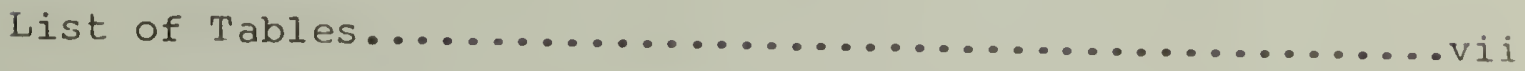

Introduction.................................

The Hippocampus and Behavioral Inhibition.......... 2

Purpose and Scope of the Present Investigation...... 1.

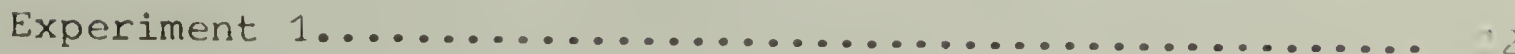

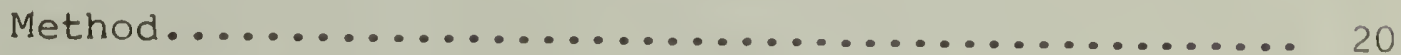

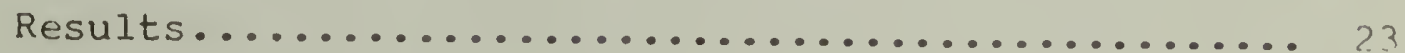

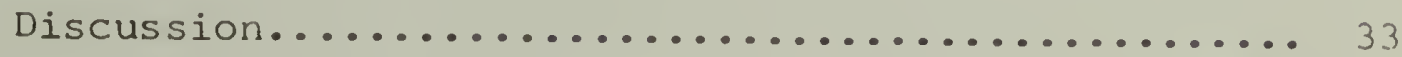

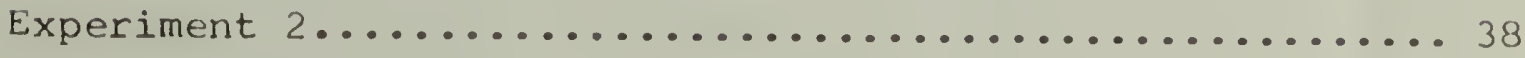

Method................................... 49

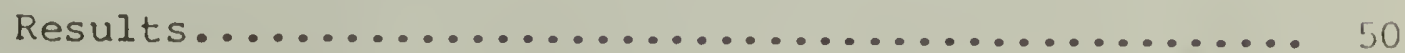

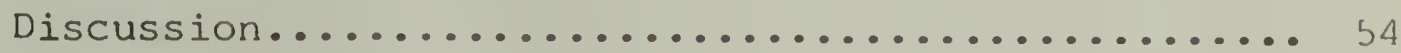

General Discussion.............................. 64

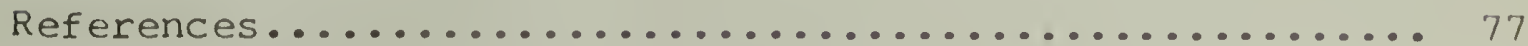

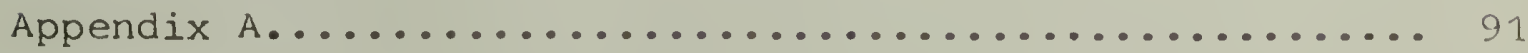

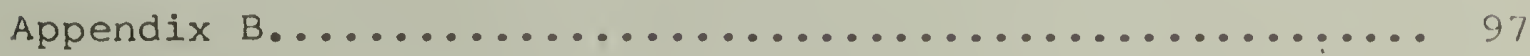

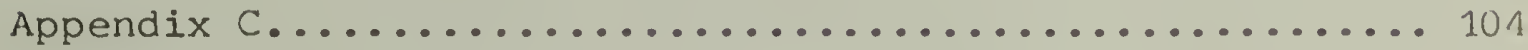

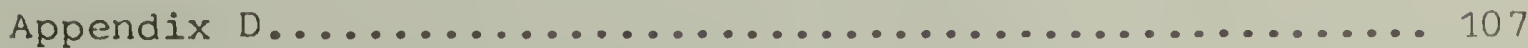


List of Figures

Figure

Page

1. Reconstructions of the lesions sustained by cortical (left) and hippocampal (right) animals. The solid and striped areas represent the minimal and maximal damage

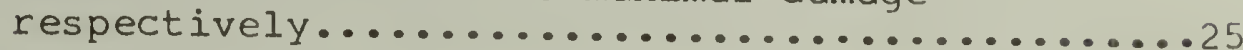

2. Mean number of responses given to light divided by the mean number of responses given to light and tone during the test phase for each of the

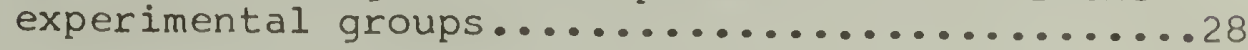

3. Mean percent conditioned responding to the tone CS for hippocampals, corticals, and normals in the blocking condition over the first three days of training in stage 1.......................

4. Mean percent conditioned responding to the light plus tone CS for hippocampals, corticals, and normals in the sit control condition over the five days of conditioning in stage 2...........32

5. Left Panels: Mean percent conditioned responding to the light (CS+) and light plus tone (CS-) for hippocampals, corticals, and normals over the 15 days of differentiation training. Right Panels: Mean percent conditioned responding to the tone for hippocampals, corticals, and normals over the three days of retardation

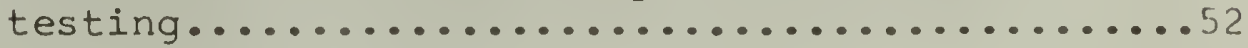




\section{List of Tables}

Table

Page

1. Kamin's Two-Stage Blocking Paradigm............14

2. Total Number of CRs to Light and Tone During

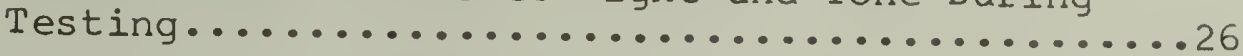

3. Possible Interpretations of Experiments Which

Employ Both Summation and Retardation Tests.....42

4. Mean Number of Trials to Criterion............55 
The hippocampal area of the mammalian telencephelon has received a considerable amount of attention in recent years. Much of this interest can be attributed to the pioneering work of Scoville and Milner (1957) and Penfield and Milner (1958) which showed a loss in the capacity of humans to store new information after hippocampal ablation. Early attempts to produce similar memorial deficits in animals, however, proved largely unsuccessful (e.g., Allen, 1940; Orbach, Milner \& Rasmussen, 1960). In general, these and numerous other studies examined the role of the hippocampus in both appetitively and aversively motivated learning tasks and found that, depending upon the nature of the task, hippocampal lesions produced either increments, decrements, or no changes in learning but not a general memory or consolidation deficit.

While this failure to find a memory deficit in animals has led to some difficulty in the interpretation of the human data (see Isacson, 1972, for a discussion of this issue), it has also provoked fruitful lines of research designed to ask what role the hippocampus plays in the control of behavior. As a result of this proliferation in research, several investigators have undertaken the arduous task of collating and interpreting the hundreds of empirical investigations relating the hippocampus to behavior. Most of these reviews have attempted to explain the role of the hippocampus in terms of 
a unitary function. For example, the hippocampus has been postulated to control: (a) olfactory functions, (b) visceral activity (Papez, 1937), (c) recent memory (Scoville \& Correll, 1973), (d) motivation (Jarrard, 1973), (e) voluntary movement (Vanderwolf, 1971), (f) cognitive maps (O'Keefe \& Nadel, 1974), and (g) behavioral inhibition (e.g., Kimble, 1968). While evidence can be gleaned to support each of these views (see Nadel \& O'Keefe, 1974, for a review of the reviews), perhaps the theory that has received the most interest, if not support, is the notion that the hippocampus plays a fundamental role in behavioral inhibition.

The Hippocampus and Behavioral Inhibition

Several theoretical viewpoints have attempted to explain the complex of behavioral changes following hippocampal destruction in terms of deficits in inhibition ( 1967; Kimble, 1968; McCleary, 1967). While each of these theories professes that the hippocampus is essential to the withholding of inappropriate behaviors, each accounts for this deficiency in somewhat different terms. Mccleary argued that hippocampal lesions disrupt motor function. Douglas suggested that the structure regulates sensory input by gating nonreinforced stimuli out of the system. Kimble simply stated that the hippocampus governs a process analagous to Pavlovian internal inhibition.

Considerable effort has been put forth to reconcile 
the various interpretations of hippocampal function; but the issue remains largely unresolved. One problem facing researchers in this area has been the failure of theorists to specify mechanisms whereby the hippocampus may take part in the process of behavioral inhibition. Recently, however, Douglas (1972) has posed a theory which specifies just such a mechanism. According to Douglas, the hippocampus is essential in assuring that stimuli which have no motivational significance (i.e., no rewarding or aversive consequences) do not maintain control over behavior. According to the model the hippocampus regulates what is attended to by modulating midbrain arousal systems. Specifically, the hippocampus is responsible for determining that a stimulus: (a) has been received, and (b) is not followed by reward or punishment. The first function is thought to occur via cortical hippocampal interaction, while the second is believed to be under the auspices of the midbrain-hippocampal arousal system. Once this information has been received the hippocampus acts as a nonreinforcement register whose purpose is to prevent the nonmotivationally significant stimulus from maintaining control over behavior. The mechanism for behavioral inhibition, then, is for the hippocampus to discharge downward and inhibit the reticular core of the brain which in turn attenuates or blocks reception of the irrelevant stimulus by tuning it out. Anatomical Evidence for Douglas' Model Several investigators (e.g., Cragg, 1965; Van Hoesen, 
Pandya, \& Butters, 1971; Whitlock \& Nauta, 1956) have reported fibers from neocortex to entorhinal cortex; others have extended this path by tracing fibers from entorhinal cortex to hippocampus (e.g., Hjorth-Simonsen \& Jeune, 1972; Raisman, Cowan, \& Powell, 1965). In addition to these cortical-hippocampal pathways, reciprocal fibers connecting the limbic system and midbrain are well documented (Guillery, 1956; Nauta, 1956). Thus it appears that the Douglas model is anatomically feasible.

Behavioral Evidence for Douglas' Model

Behaviorally, removal of the hippocampus should be disruptive in any situation which requires the organism to tune out, and withhold responding to, a nonreinforced stimuli. The findings from a number of experiments, employing a variety of behavioral tasks, can be construed as supporting the idea that the hippocampus serves this function.

Extinction. Isaacson, Douglas, and Moore (1961) showed that hippocampectomized rats, when compared with cortically ablated or unoperated controls, exhibited a greater resistance to extinction in an active avoidance situation. Kimble (1967) reported similar results in a $Y$ maze. In addition, hippocampectomized rats trained on a CRF schedule emit more responses than controls during extinction (Rabe \& Haddad, 1968; Swanson \& Isaacson, 1967) and spontaneous recovery (Niki, 1965) of bar pressing. 
Discrimination learning. Douglas and Pribram (1966) reported data to suggest that although hippocampal animals have no difficulty in learning tasks which require increased responding in the presence of stimuli which have been associated with reinforcement, they are greatly impaired in behaviors which necessitate a decrease in responding in the presence of stimuli which predict neither reward or punishment. In one such experiment (Douglas \& Pribram, 1966) a two-choice brightness discrimination was presented to monkeys (Stage I). The results indicated that hippocampal animals learned the task as well as normals. In Stage II of this study, each animal was presented with three possible stimulus configurations: (A) the $S+$ and $S$ - from Stage $I,(B) S+$ and a novel stimulus, and (C) $\mathrm{S}$ - and a novel stimulus. When presented with configurations $\mathrm{A}$ or $\mathrm{B}$, both hippocampal and normal animals showed a preference for the St. When configuration $C$ was presented, however, normal animals showed a preference for the novel stimulus while hippocampectomized monkeys responded equally to both stimuli.

The interpretation of these data was that normal animals acquired the discrimination in Stage $I$ by both learning to respond in the presence of $S+$ and learning not to respond in the presence of S-. Hippocampals, on the other hand, acquired the discrimination strictly by learning to respond in the presence of $\mathrm{S}+$. The authors attributed the failure to 
find any cifferences in rate of acquisition in Stage $I$ to the relative ease of the task. To account for the data in Stage II, Douglas and Pribram suggested that in both configurations $A$ and $B$ learning to respond in the presence of $S+$ was a sufficient condition for behaving appropriately. In configuration $C$, however, learning not to respond in the presence of $\mathrm{S}$ - was necessary for the discrimination to be formed and this is why it is here that animals with hippocampal lesions showed their deficiency.

In a related experiment (Douglas, et al., 1969) monkeys were taught: a series of simultaneous brightness discriminations, eac's consisting of one $S_{+}$and a varying number of $S_{-}-S$ (each S-, however, was identical to the others). In the twochoice problem hippocampals and normals, again, performed about the same; but as the number of $\mathrm{S}-\mathrm{s}$ increased, the performance of lesioned animals deteriorated to about the chance level while that of normals remained essentially unchanged. This may be taken as further evidence that hippocampectomized monkeys do not learn to withhold responding to nonreinforced stimuli.

Reversal learning. Consistent with the Douglas and Pribram findings are studies which report that animals with hippocampal lesions are impaired in discrimination reversal even though the initial discrimination was readily acquired (Kimble, 1967; Kimble \& Kimble, 1965; Thompson \& Langer, 1963). This difficulty in reversal learning was attributed 
to the fact that hippocampal animals could not "tune out" the previously reinforced cue $\left(S_{+}\right)$even though it no longer signalled reinforcement. Olton (1972) has further reported that even when hippocampal lesions were preceded by extensive reversal training the deficit was present.

Complex maze learning. Dennis and Sollenberger (1934) suggested that complex maze learning is almost entirely mediated by inhibition of entry into error pathways. Given this interpretation, hippocampal animals should be greatly impaired in learning this task. Several studies, beginning with Kaada, Rasmussen, and Kviem (1961), have presented data to support this view (e.g., Hostetter \& Thomas, 1967; Jackson \& Strong, 1969). In addition, Jarrard and Lewis (1967) reported that this deficit did not vary as a function of the intertrial interval, this suggesting that it was not the result of a general memory deficit.

Habituation. A variety of behavioral situations thought to involve habituation are adversely affected by hippocampectomy. For example, several studies have shown that animals with hippocampal lesions continue to explore new environments after control animals have ceased (Jarrard \& Bunnell, '1968; Leaton, 1967; Sengstake, 1968). Hippocampals have also been shown to lever press at higher rates than controls for a brief flash of light (Kamback, 1967).

A number of researchers have reported that hippocampal lesions disrupt habituation of the cardiac component of the 
orienting response (OR), (Karmos \& Gastryan, 1962; Sandwald, et al., 1970), although others have found no deficit in the habituation of the OR even though habituation of activity to a novel environment was impaired (Jarrard \& Korn, 1969).

Spontaneous alternation. When given consecutive trials in a $\mathrm{T}$ maze, normal animals show a significant tendency to enter opposite alleys on alternate trials. This spontaneous alternation is thought to be due to habituation to the most recently entered alley (Glazner, 1953). Given this interpretation and the findings of other studies which indicate deficits in habituation in hippocampectomized animals, hippocampal lesions should disrupt spontaneous alternation. In fact, a substantial body of literature shows that animals with hippocampal lesions do not alternate, but rather perseverate in their initial response (Douglas \& Isaacson, 1964; Kirkby, Stein, \& Kimble, 1967; Leaton, 1967; Stevens, 1973). Furthermore, this effect is robust in that it is readily observed if damage is induced in either infancy or adulthood or if the lesions are produced in one or two stages (Douglas \& Peterson, 1969).

Latent inhibition. While it can be argued that each of the aforementioned situations entails inhibition of responding to a nonreinforced stimulus, a somewhat more direct test of this hypothesis was carried out by Solomon and Moore (1975). In this experiment, the effects of hippocampectomy were evaluated in a latent inhibition paradigm. Latent 
inhibition (LI) refers to the finding that a series of nonreinforced preexposures to a stimulus retards conditioning to that stimulus when it is subsequently paired with a UCS (see Lubow, 1973; Weiss \& Brown, 1974, for reviews).

There have been several recent experimental investigations of the latent inhibition phenomena in the rabbit nictitating membrane response (NMR) preparation (Reiss \& Wagner, 1972; Siegel, 1972; Solomon et al., 1974 a \& b). In general these studies support the conclusion from other conditioning preparations (cf., Rescorla, 1971) that the retardation of conditioning is attributable to the preexposed CS losing salience through a tuning-out process that resembles habituation. Given this interpretation, the Douglas model predicts that the hippocampus is critical to the formation of a latent inhibitor. The Solomon and Moore study confirmed this prediction. Specifically, they reported that while 450 tone preexposures resulted in a decrement in conditioning for normal and cortical ablated rabbits, hippocampal rabbits showed no such deficit. In fact, hippocampal rabbits showed slightly superior conditioning when compared with nonpreexposed hippocampal ablated controls. Similar results have been reported in a two-way active avoidance situation by Ackil et al., (1969)

Although the Solomon and Moore study appears to support the view that the hippocampus acts as a nonreinforcement 
register, before this conclusion can be drawn two alternative interpretations must be ruled out. Specifically, since the rate of conditioning is directly related to both the magnitude of the UCS and the intensity of the CS (see Gormezano and Moore, 1969, for a review), the finding in the Solomon and Moore study that preexposed hippocampal animals conditioned faster than preexposed corticals and normals might be attributed to exaggerated responsiveness to the tone CS or exaggerated sensitivity to the shock UCS in hippocampals.

Either of these alternatives becomes especially tenable in light of Jarrard's (1973) proposal that the hippocampus is involved in motivational processes. For example, McNew and Thompson (1966) showed that hippocampal animals reacted more vigorously to shock during acquisition of an avoidance response. Blanchard and Fial (1968) reported differences (though slight) in thresholds for jump, flinch, vocalization, and crouching in rats. Specifically, hippocampal damaged rats jumped at a lower shock level than normals, vocalized at a higher level, and, in general, showed less crouching following shock. Other studies have reported that hippocampal lesions do not alter shock threshold itself, but do lead to an "overreaction" to shocks which are well above threshold (e.g., Schlosberg, Johnson \& Lash, 1968). Based on these and other studies, Jarrard concluded that hippocampal lesions produce only small differences in shock thresholds per se, but 
cause heightened reactivity to shocks that are above threshold. The data on stimuli which are typically used as CSs are similar to those on shock threshold. In general, experiments which have tested reactivity to visual and auditory stimuli indicate that hippocampectomized rats do not overreact to light (Green et al., 1967; Kaplan, 1968) or tone (Gotsick, 1969) stimuli unless these, too, are well above threshold (Ireland \& Isaacson, 1968).

To test the possibility that hippocampal lesions altered the sensitivity to the CS or UCS, the Solomon and Moore study included postacquisition threshold tests to the tone, and tests of habituation and dishabituation to the eye shock UCS. The authors reported virtually identical auditory thresholds in hippocampal, cortical, and normal animals, suggesting that the failure to find the latent inhibition effect among hippocampectomized rabbits is not related to an alteration in CS threshold. Similarly, no differences were found as a function of lesion type with respect to the rate of habituation or dishabituation to the shock UCS. Insofar as these tests can be taken as indices of shock reactivity, they suggest that disruption of LI in hippocampals is not due to heightened UCS sensitivity. Thus it appears that the failure to find latent inhibition in hippocampectomized rabbits was due to their inability to tune out the nonreinforced preexposed stimulus. 
Purpose and Scope of the Present Investiqation

Since earlier work in our laboratory supports the view that the hippocampus is an integral part of a neural system which governs the tuning out of nonreinforced stimuli, the present investigation further examined the role of the hippocampus in this process by investigating the effects of hippocampal lesions on other behaviors in which such attentional processes might occur. Specifically, the present series of experiments examined the effects of dorsal hippocampal ablation on blocking and conditioned inhibition of the rabbit's nictitating membrane response.

\section{EXPERIMENT 1}

Blocking was initially described by Palladin in 1906, who was at the time working in Pavlov's laboratory (see Razrin, 1965). The more recent interest in the phenomena, however, is largely attributable to the work of Kamin (1968, 1969).

The typical blocking paradigm consists of a two-group design as shown in Table 1. In Stage 1 the experimental group is presented with Stimulus A paired with the UCS until conditioning is well established. The control group is simply placed in the apparatus with no CS or UCS presentations. During Stage 2 both groups are conditioned to a compound consisting of $A$ and a new stimulus, B. After both experimental and control groups show a high level of conditioning to 
the compound, the test phase is introduced. During testing both groups are presented with stimulus B nonreinforced. In general, it is found that while the control group exhibits excitatory conditioning to stimulus B, i.e., B elicits a CR, the experimental group shows little if any responding to the same stimulus. Apparently a prior history of reinforcement to stimulus A "blocks" conditioning to $B$ when the AB compound is reinforced.

Empirical Demonstrations of Blocking

Kamin (1968), employing a version of the Estes and Skinner (1941) conditioned emotional response procedure (CER), demonstrated blocking of a light by a noise in rats. More recently, several other investigators have shown blocking to be both a reliable and a robust phenomenon. For example, Gray and Appignanisi (1973), also using the CER procedure, have produced the blocking effect as have Bakal, Johnson, and Rescorla (1974). Similarly, blocking of a light by a tone has been demonstrated in the rabbit NMR preparation (Marchant \& Moore, 1973).

In operant tasks which generally employ a discrimination paradigm to show blocking, the procedure is as follows: in Stage 1 the experimental group learns a discrimination in which responding in the presence of cue A produces reinforcement; in Stage 2 both experimental and control groups learn a discrimination in which both cue $A$ and a new cue, B, predict 
TABLE 1

KAMIN'S TWO-STAGE BLOCKING PARADIGM

\begin{tabular}{|l|c|c|c|}
\hline \multirow{2}{*}{ EXPERIMENTAL } & STAGE 1 & & STAGE 3 (test) \\
& $\mathrm{A}+$ & $\mathrm{AB}+$ & $\mathrm{B}-$ \\
\hline CONTROL & - & $\mathrm{AB}+$ & $\mathrm{B}-$ \\
& & & \\
\hline
\end{tabular}


reinforcement -- that is, cue B gives redundant information; finally, in Stage 3 animals are tested to see what, if anything, was learned about cue B. A number of experiments using this or similar tasks have generally shown that in operant as in Pavlovian situations the blocking effect is readily observed (see Sutherland \& Mackintosh, 1971, for a review of the operant literature).

Attentional Theories of Blocking

Kamin (1968) originally suggested that in the blocking procedure prior conditioning to element A causes the animal "not to notice" element B when presented in compound with A. The failure to notice B, then, would clearly preclude conditioning to it. More recently, however, evidence to militate against the failure to notice hypothesis has been presented. Kamin (1969) reported data to indicate that animals in his experiments do notice stimulus $B$ on the first presentation of the compound. Specifically, he reported that following the pairing of stimulus $A$ with shock, rats in the blocking group exhibited a high level of conditioning. On the first trial in which the $A B$ compound was presented, however, the magnitude of the CR was significantly reduced. As Kamin pointed out, this clearly indicates that the animal attended to stimulus $B$ on at least the first presentation of the compound.

In view of these findings both Kamin (1969) and 
Mackintosh (1973) have expoused the view that the animal does in fact notice the redundant stimulus, but does not condition to it since it provides no new information regarding the reinforcing event. That is to say the motivationally significant event, shock, is already signalled by $A$ and attending to $B$ has no adaptive value to the organism. There are several lines of research which support this hypothesis. Kamin (1969) reported a series of experiments in which the UCS in Stage 2 differed from that used in Stage 1 . In one experiment the UCS intensity was raised during the second stage. Since the compound now signalled new information, a more intense shock, it was expected that each element would take on excitatory properties, thus eliminating blocking. The results of the experiment confirmed this prediction (Kamin, 1969). Similarly, blocking was eliminated if a second shock was presented five seconds after the delivery of the UCS. Other experimenters (Bakal, Johnson, \& Rescorla, 1974; Mackintosh \& Turner, 1971) also reported data which shows that increasing the UCS intensity in Stage 2 disrupts blocking.

In summary, then, there is substantial evidence to suggest that in the two-stage blocking paradigm the failure of stimulus $B$ to take on excitatory strength is due to its inability to predict a new motivationally significant event. It has also been demonstrated that on the trial in which $B$ is first presented in compound with A, the organism attends 
to B. This attention, however, is eliminated by subsequent AB trials. Taken together, these two bits of information suggest that some active mechanism is responsible for the tuning out of stimulus B. It was the purpose of the present experiment to determine if the physiological mechanisms involved in this process are similar to those operating when one stimulus is presented prior to conditioning and not reinforced as in latent inhibition. Specifically, the present experiment examined the role of the dorsal hippocampus of the rabbit in Kamin's two-stage blocking paradigm. It was expected that if, in fact, the tuning-out process in this situation is similar to that in latent inhibition, then hippocampectomy should reduce the blocking effect. The Rescorla-Wagner Model and Blocking

Rescorla and Wagner (1972) proposed a contiguity theory of conditioning which explains blocking in terms of associative rather than attentional mechanisms. The model assumes that a UCS or reinforcer can support only a certain amount of conditioning. The specific amount is known as the asymptote and referred to as $\boldsymbol{\lambda}$. When CS (A) is paired with the UCS, the amount of associative strength $\left(\Delta \mathrm{v}_{\mathrm{A}}\right)$ that the CS can acquire on any particular trial is a function of two variables: $\lambda$, and the amount of associative strength CS (A) already possesses at the beginning of the trial $\left(\mathrm{V}_{\mathrm{A}}\right)$. In addition, since CSs of different salience will alter the rate of 
conditioning, a parameter exists which takes into account varying CS intensities. This parameter, known as $\alpha$, is restricted to taking values between 0 and 1 . Similarly, different UCSs alter the rate of conditioning and the model takes this into account by including a parameter $\beta$, which is roughly indicative of the magnitude of the UCS. Like $\alpha$, $\beta$ can take on any value between 0 and 1 . The model for any trial, then, is as follows:

$$
v_{A}=\alpha \beta\left(\lambda-v_{A}\right)
$$

In essence, this model differs little from earlier continuity theories of learning (e.g., Hull, 1943). To explain blocking, however, the Rescorla-Wagner model makes one additional assumption and it is here that it departs from previous mathematical accounts of conditioning.

Early conditioning models (e.g., Hull, 1943) have implied that if several CSs are concurrently presented on a particular trial (e.g., stimuli A \& B) then the associative value of each component will be modified until each reaches $\lambda$. Rescorla and Wagner assume that the associative value of each component will be modified only until the collective value of the compound reaches 2 . It follows then that if compound $A B$ is paired with a UCS the change in strength to each component will be taken as a function of $V_{A B}$ and not that of the individual stimuli. The equations here are: 


$$
\begin{aligned}
& V_{A}=\alpha \beta\left(\lambda_{1}-V_{A B}\right) \\
& V_{B}=\alpha \beta\left(\lambda_{2}-V_{A B}\right)
\end{aligned}
$$

where: $V_{A B}=V_{A}+V_{B}$

In the blocking procedure, if $\mathrm{CS}_{\mathrm{A}}$ is conditioned to asymptote in Stage 1, then when Stage 2 is entered $V_{A B}$ should already be high due to the contribution of $\mathrm{V}_{\mathrm{A}}$; hence there should be little opportunity for $V_{B}$ to be incremented. Consequently, $C S_{B}$ takes on no excitatory strength.

While the Rescorla-Wagner Model can account for most of the behavioral data on blocking (e.g., Marchant \& Moore, 1973), it may have some difficulty accounting for the possible elimination of blocking by hippocampectomy. Specifically, the model incorporates only one mechanism whereby hippocampal lesions could disrupt blocking: by raising $\boldsymbol{\lambda}$, the asymptotic value of the UCS. If this occurs, it is possible that animals with hippocampal lesions will not readily achieve the asymptote of the UCS during initial conditioning to $\mathrm{CS}_{\mathrm{A}}$ in Stage 1. To test this possibility, acquisition of the CR to the tone CS in Stage 1 was monitored. If hippocampal lesions raise $\lambda$ then: (a) the acquisition curves for animals with hippocampal lesions should be steeper than those for cortical damaged or normal rabbits, and (b) the total number of CRs to tone should be greater for hippocampals than for cortical or normal controls. 


\section{Method}

Animals

The subjects for this experiment were 30 experimentally naive male and female New Zealand albino rabbits (oryctolagus cuniculus) weighing between 2.8 and $3.2 \mathrm{~kg}$ at the time of surgery. Animals were individually housed and maintained on food and water ad libitum.

\section{Surgery}

Animals in the hippocampal groups were anesthetized via an intramuscular injection of chlorpromazine $(4 \mathrm{mg} / \mathrm{kg}$ ) followed one hour later by sodium pentobarbitol ( $22 \mathrm{mg} / \mathrm{kg}$ ) injected intravenously through the marginal ear vein. Following subcutaneous injections of a local anesthetic (Xylocaine) across the scalp, the animal was placed in a Kopf headholder and the skin and fascia were removed to expose the skull. By using a drill and rongeurs, holes were opened bilaterally which extended from $2 \mathrm{~mm}$ posterior to bregma to $2 \mathrm{~mm}$ anterior to lambda in the rostral-caudal plane, and $3 \mathrm{~mm}$ off the midIine to $1 \mathrm{~mm}$ medial to the temporal bone in the medial-lateral plane. The dura was then incised and retracted and the underlying cortex, corpus callosum, and hippocampus were removed by gentle aspiration. Special care was taken not to damage the head of the caudate nucleus or the dorsal thalamus. After bleeding had stopped, the wound was packed with Gelfoam which had been soaked in Thrombin. Neosporin 
was then applied to the skull to help combat infection and the incision was closed with wound clips. Finally, to further aid in combating infection all animals were given intramuscular injections of Bicillin ( 300,000 units) 24 hours prior to surgery and again 48 hours post-surgery.

Animals in the cortical lesioned groups underwent an identical procedure except that only the cortex and corpus callosum were removed.

All animals were given a minimum of 21 days to recover before the onset of behavioral training and testing. Apparatus

The apparatus and methods used to condition the rabbit's nictitating membrane response are essentially those described by Gormezano (1966). Basically, four animals were run simultaneously in individually ventilated and sound attenuated chambers. A panel in front of each chamber housed two lights, each mounted behind a translucent milk white screen, and a speaker which was used to deliver the tone CS.

Each rabbit was restrained in a plexiglas box with an adjustable plate and ear clamp securing the head, and a second plate placed over the animals back to restrict general movement. A small nylon loop was sutured through the right NM and attached to the shaft of a minitorque potentiometer (Conrac 85153) which was mounted on top of the animals head. In this way lateral movement of the NM was transduced into 
a dc signal which was subsequently recorded on a Grass model 5D four channel polygraph located in an adjacent room. A conditioned response was defined as a pen deflection of at least $1 \mathrm{~mm}$ (corresponding to a NM movement of less than $1 \mathrm{~mm}$ ) occuring in the CS-UCS interval.

The CSs employed in this experiment were either a $76 \mathrm{~dB}$ $\mathrm{SPL}, 1200 \mathrm{~Hz}$ tone, a $6.0 \mathrm{vdc}$ light, or a compound consisting of both. The duration of the CS was a constant $450 \mathrm{msec}$. The UCS was a 2-mA shock of $50 \mathrm{msec}$ duration delivered via two stainless steel wound clips implanted superficially in the skin: one immediately below and the other immediately posterior to the right eye. The intertrial interval was a constant 30 seconds and the interstimulus interval remained $450 \mathrm{msec}$ throughout.

\section{Procedure}

Following suturing of the right NM all rabbits were habituated to the restraint of the apparatus for 50 minutes on Day 1. Half of the animals in the hippocampal, cortical, and normal groups were randomly assigned to either a blocking or control group. Thus the experiment consisted of a total of six groups ( 5 subjects per group) comprising a $2 \times 3$ factorial design. The groups were: Hippocampal Sit Control (H-SIT), Hippocampal Blocking (H-BLO), Cortical sit Control (C-SIT), Cortical Blocking (C-BLO), Normal Sit Control (N-SIT), and Normal Blocking $(\mathrm{N}-\mathrm{BLO})$. Animals in the blocking groups were given 100 conditioning trials per day to the tone CS 
until two consecutive days were recorded in which CRs occurred on $90 \%$ or more of the trials (either 3 or 4 days of tone acquisition). Animals in the control groups simply sat in the apparatus with no CS or UCS presentations for a corresponding amount of time.

During Stage 2 animals in both the experimental and control groups received five days of conditioning ( 100 trials per day) to a compound CS consisting of the tone from Stage 1 and a light. On the day following completion of stage 2 , testing began and proceeded for two days. Each day consisted of 50 light (nonreinforced) and 50 tone (nonreinforced) trials presented in an unsystematic order.

Shortly after the conclusion of testing, operated animals were sacrificed by sodium pentobarbitol overdose and perfused intracardially with $0.9 \%$ saline followed by $10 \%$ formalin solution. The brains were removed, stored in formalin, and subsequently embedded in low viscosity nitrocellulose. Coronal sections were taken through the extent of the lesion at $40 \mu$. At the most anterior and posterior aspects of the lesion every second section was mounted, while every fourth section was mounted in the central portion of the damaged area. All tissue was then stained with cresyl violet. $\underline{\text { Results }}$

\section{Histology}

Examination of brain sections for both Experiments 1 
and 2 revealed that all animals in the hippocampal groups sustained virtually complete bilateral destruction of the dorsal hippocampus. Although the postero-ventral portion of the structure was spared, isolation of the hippocampus from the fornix was achieved since the fimbria were bilaterally sectioned in all cases. It should be noted, however, that this does not preclude the possibility of the ventral hippocampus interacting with other structures via the hippocampalentorhinal path (Hjorth-Simonsen, 1971).

Damage to structures other than the hippocampus and overlying cortex was minimal. Two animals sustained unilateral damage to the head of the caudate nucleus. One animal exhibited a unilateral depression of the caudate due to the formation of scar tissue and one animal showed a similar unilateral depression of the dorsal thalamus.

Animals in the cortical groups generally showed more damage to the cortex than did hippocampal animals. In only one case did a cortical lesioned animal show damage (unilateral) to the hippocampus. This rabbit, however, did not behave differently than other animals in the same treatment condition. Reconstructions showing the minimal and maximal extent of the lesions are shown in Figure 1. Blocking

Table 2 shows the mean total number of responses to light and tone for each of the six experimental conditions. 
FACE PAGE FOR FIGURE 1

Figure 1. Reconstructions of the lesions sustained by cortical (left) and hippocampal (right) animals. The solid and striped areas represent the minimal and maximal damage respectively. 

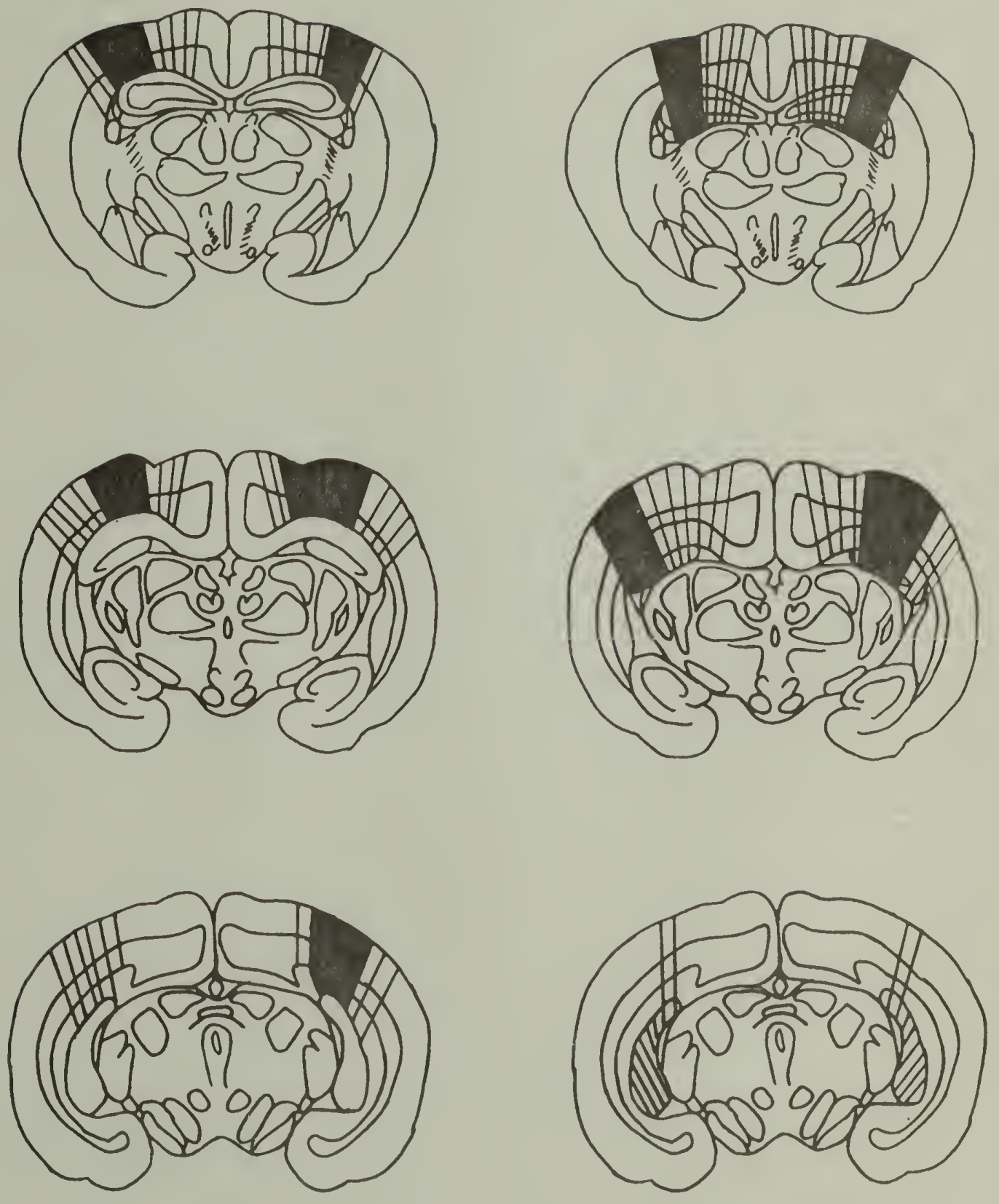
TABLE 2

TOTAL NUMBER OF CRS TO LIGHT AND TONE DURING TESTING

\begin{tabular}{|c|c|c|}
\hline Group & Light & Tone \\
\hline H-BLO & 302 & 348 \\
\hline H-SIT & 223 & 250 \\
\hline C-BLO & 120 & 413 \\
\hline C-SIT & 261 & 294 \\
\hline N-BLO & 65 & 405 \\
\hline N-SIT & 201 & 326 \\
\hline
\end{tabular}


Since the absolute number of responses emitted during testing varied across animals, a ratio in which the number of CRs emitted to light during the test phase was divided by the total number of CRs $(L / L+T)$ was used as the measure of blocking. Thus a score below .5 indicates less responding to light than tone (i.e., blocking); a score above .5 indicates more responding to light than tone; and a score of .5 is indicative of equal amounts of responding to each CS.

Figure 2 depicts the mean suppression ratios for animals in each of the six experimental groups. Both cortical and normal animals showed blocking as indicated by lower ratios in rabbits given tone conditioning in Stage 1 (Groups C-BLO and $\mathrm{N}-\mathrm{BLO}$ ) than those in the corresponding sit control groups (Groups C-SIT and N-SIT). In hippocampal lesioned rabbits, however, the blocking effect was not present. Hippocampal lesioned rabbits in both the blocking ( $\mathrm{H}-\mathrm{BLO})$ and control conditions (H-SIT) exhibited identical mean ratios.

A two-way analysis of variance (ANOVA) on the mean ratios revealed significant lesion $(\underline{F}=14.59, \underline{\mathrm{d} f}=2 / 24, \underline{p}<.001)$ and treatment $(\underline{F}=27.25, \underline{d f}=1 / 24, \underline{p}<.001)$ main effects as well as a significant interaction $(\underline{F}=6.82, \underline{d f}=2 / 24, \underline{p}<.005)$. A test of simple effects indicated that the significant Lesion $\mathrm{X}$ Treatment interaction was a result of the failure to find the blocking effect in hippocampectomized rabbits. Specifically, a comparison between hippocampal and cortical 
FACE PAGE FOR FIGURE 2

Figure 2. Mean number of responses given to light divided by the mean number of responses given to light and tone during the test phase for each of the experimental groups. 


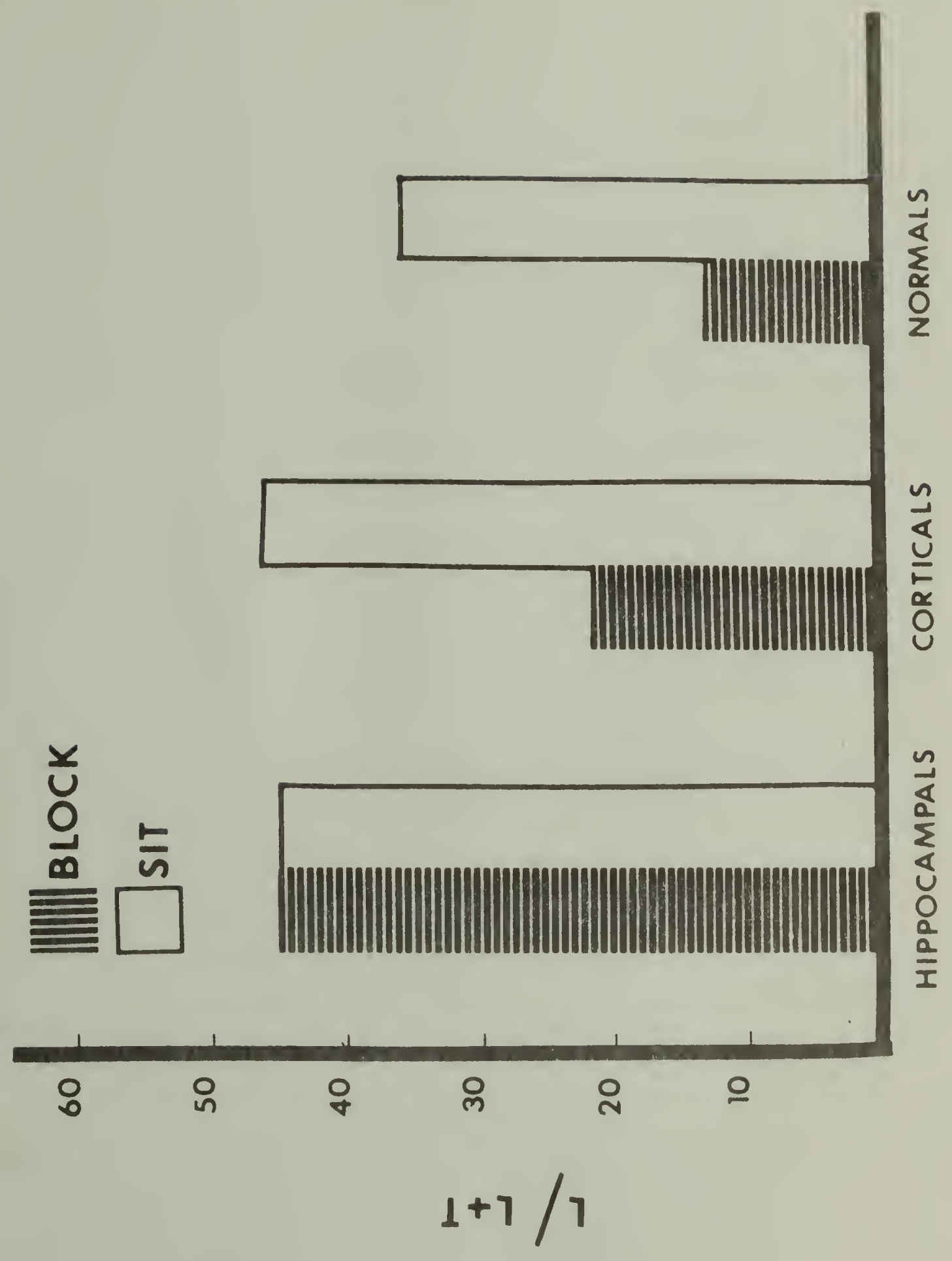


animals revealed a significant Lesion $x$ Treatment interaction $(\underline{F}=10.6, \underline{\mathrm{d} f}=1 / 24, \underline{\mathrm{p}}<.01)$ as did a comparison between hippocampals and normals $(\underline{F}=9.88, \underline{\mathrm{d} f}=1 / 24, \underline{\mathrm{p}}<.01)$. When normals and corticals were compared, however, no significant interaction was found $(\underline{F}=\langle 1, \underline{d f}=1 / 24, \underline{p}\rangle .05)$.

The finding of a significant lesion-type main effect also appears attributable to the increased ratio in Group H-BLO. Newman-Kuels pairwise comparisons, which collapsed across treatment conditions confirmed this observation by indicating that hippocampal lesioned animals exhibited significantly higher ratios than either corticals $(\underline{p}<.01)$ or normals $(\mathrm{p}<.01)$.

Tone Acquisition

Acquisition curves for the three days of conditioning to the tone CS are shown in Figure 3.

To determine if lesion type had any effect on either the rate of acquisition or the total number of CRs emitted during acquisition, an ANOVA was conducted in which lesion type served as a between groups variable and trial blocks as a within groups variable. Since all animals were responding at virtually $100 \%$ by acquisition Day 3, only data from Days 1 and 2 were analyzed. Results of the analysis indicated a significant blocks effect $(\underline{\underline{F}}=23.83, \underline{\mathrm{df}}=9 / 108, \underline{\mathrm{p}}(.001)$; however, no differences were found as a function of lesion type $(\underline{F}=\langle 1, \underline{d f}=2 / 12, \underline{p}\rangle .05)$ or the interaction of the two variables $(\underline{E}=1.06, \underline{d f}=18 / 108, \underline{p}) .05)$. 
Inspection of Figure 3 shows that the significant blocks effect resulted from an increase in the number of CRs as the number of CS-UCS pairings increased. Of greater importance, however, is the failure to find a significant lesion main effect or Lesion X Block interaction. This suggests that neither the total number of CRs, nor the rate of acquisition of the CR varied as a function of lesion type. $\underline{\text { Light }+ \text { Tone Acquisition }}$

Figure 4 depicts the rate of acquisition to the light + tone (LT) compound in Groups H-SIT, C-SIT and N-SIT. Animals in the blocking groups are not included in these curves since prior conditioning to the tone during stage 1 caused them to respond at virtually $100 \%$ throughout LT conditioning. An ANOVA, which treated blocks as a within groups variable and lesion type as a between groups variable, was conducted to determine if rates of acquisition or total CRs differed as a function of lesion type. As in the case of tone acquisition, since all animals were responding at $100 \%$ by Day 3, only data from the first two days were analyzed. Results of the analysis yielded exactly the same set of statistical decisions as those for tone acquisition: a significant blocks effect $(\underline{F}=20.48, \underline{d f}=9 / 108, \underline{p}<.001)$, but no reliable differences as a function of lesion type $(\underline{F}=2.21, \underline{d} f=2 / 12$, p $>.05)$, or the interaction of the two variables $(\underline{F}=1.32$, df $=$ $18 / 108, p>.05)$. This suggests that as in the case of tone 
FACE PAGE FOR FIGURE 3

Figure 3. Mean percent conditioned responding to the tone CS for hippocampals, corticals, and normals in the blocking condition over the first three days of training in stage 1. 


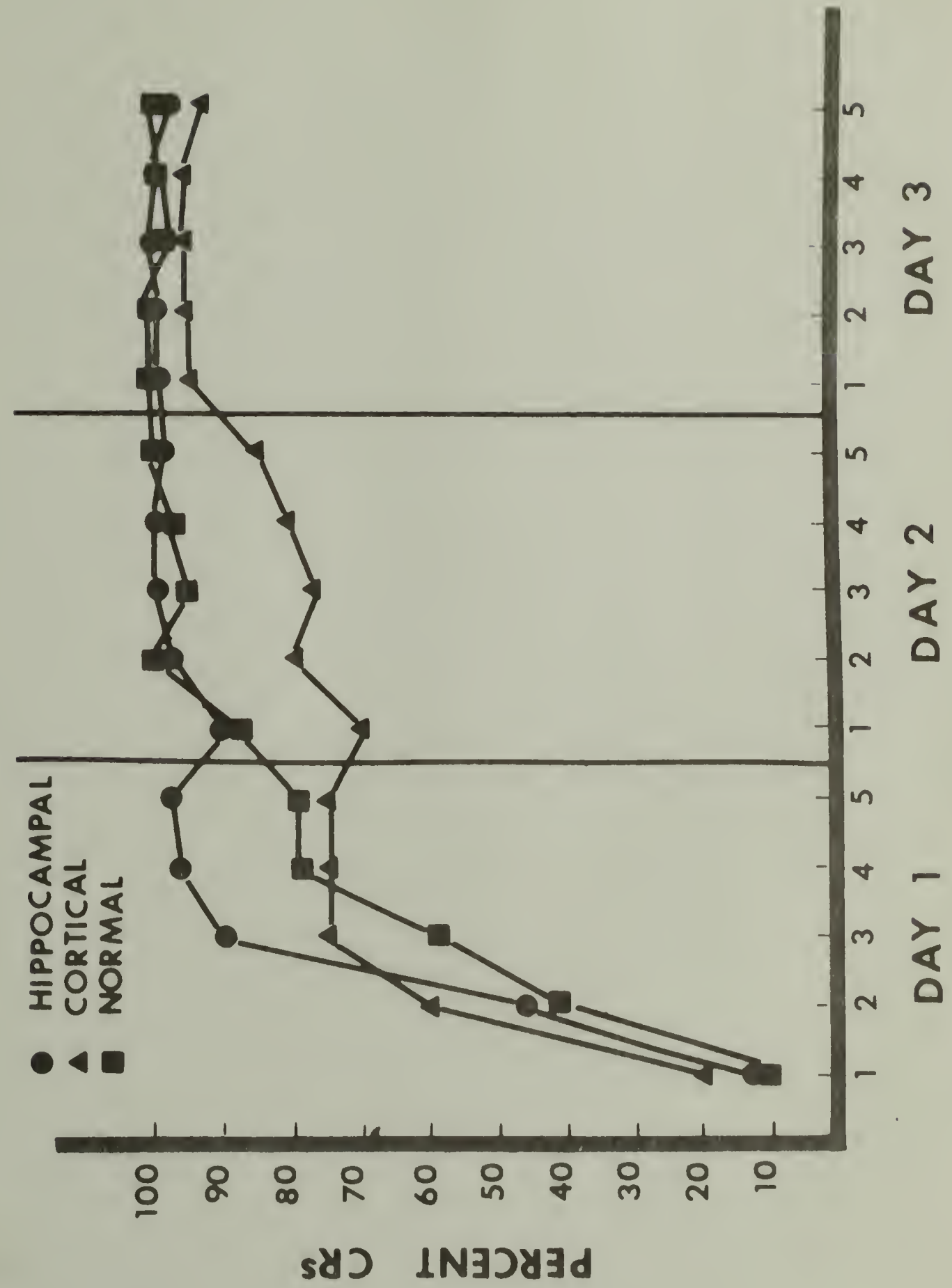


FACE PAGE FOR FIGURE 4

Figure 4. Mean percent conditioned responding to the light plus tone CS for hippocampals, corticals, and normals in the sit control condition over the five days of conditioning in Stage 2 . 


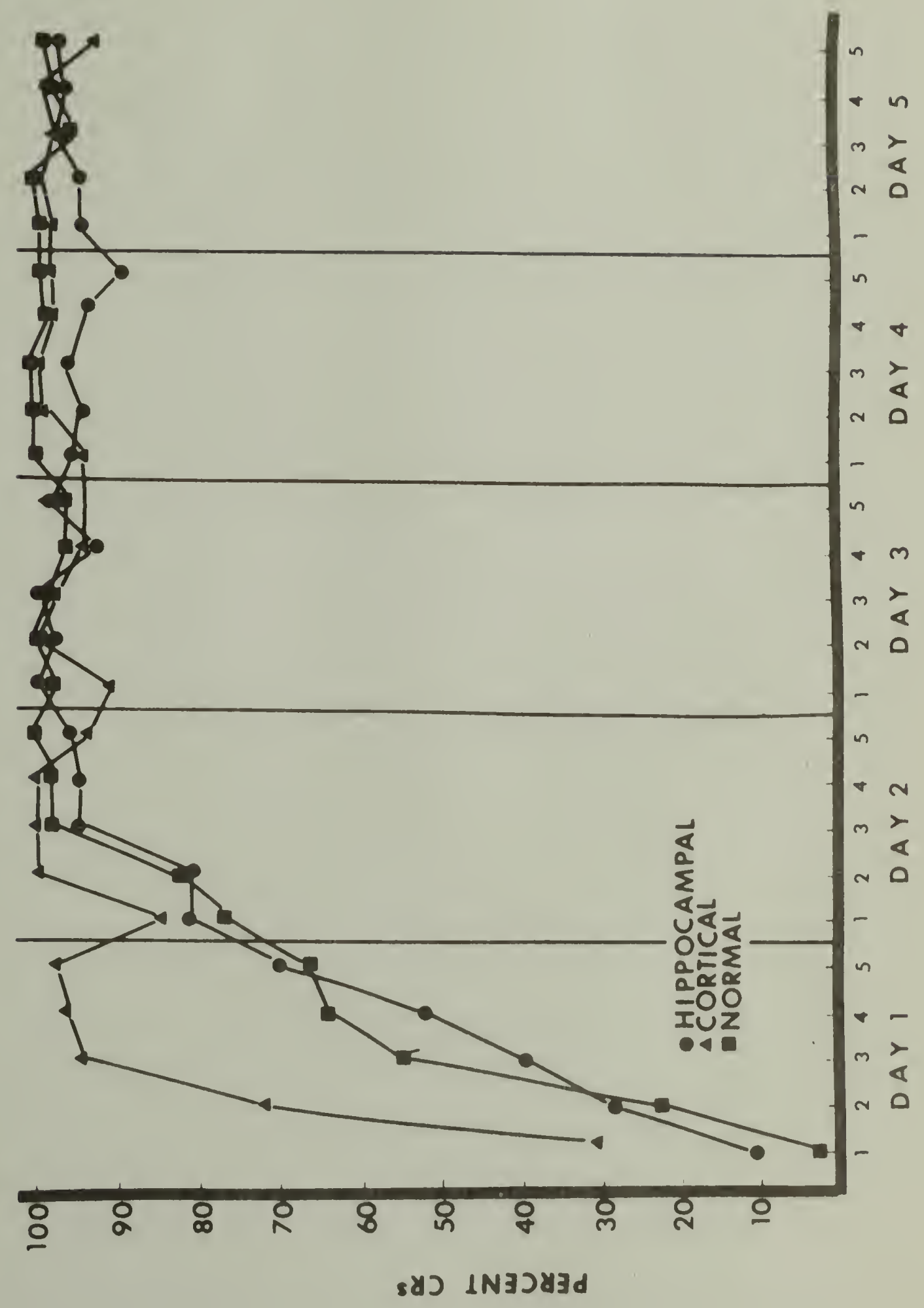


acquisition, LT conditioning is not affected by hippocampal or cortical lesions.

\section{Extinction}

To determine if the total number of CRs given to the tone during the two days of testing varied as a function of lesion type or treatment condition, a two-way ANOVA was performed. The results indicated that animals in the blocking groups gave significantly more CRs than their sit control counterparts $(\underline{F}=5.91, \underline{\mathrm{d}}=1 / 24, \underline{\mathrm{p}}<.025)$; however, this trend did not vary as a function of lesion type as indicated by the failure to find a significant Lesion $X$ Treatment interaction $(\underline{F}=\langle 1, \underline{d f}=2 / 24, \underline{p}\rangle .05)$. Furthermore, while animals in both the normal and cortical groups gave more CRs than rabbits in the hippocampal groups $(\bar{X}=73.1,70.7$, and 59.8, respectively), these differences did not approach statistical significance $(\underline{F}=1.02, \underline{d f}=2 / 24, \underline{p}>.05)$.

\section{Discussion}

The major findings of this experiment are: (1) hippocampal lesions greatly reduced the blocking of a light by a tone, (2) acquisition of a tone CS or a light + tone CS were not significantly affected by hippocampal lesions, and (3) extinction of the CR to the tone CS was not significantly affected by hippocampal lesions.

The finding that hippocampal lesions disrupt blocking is generally consistent with the idea that the hippocampus 
is part of a neural system responsible for tuning out motivationally nonsignificant stimuli. Prior work in the rabbit NMR preparation (Solomon \& Moore, 1975) indicated that hippocampal ablation disrupts the tuning out of a nonreinforced preexposed stimulus. Specifically, the authors reported that although preexposure to a tone CS retarded subsequent conditioning of the NMR in cortical lesioned and normal rabbits, this effect was not present in animals with hippocampal damage. To explain these results Solomon and Moore suggested that in normals and corticals, since the tone did not predict a motivationally significant event during the preexposure stage, it underwent a loss of salience due to a tuning out process resembling habituation. In hippocampal lesioned rabbits, however, this process was disrupted. The present experiment extends findings to the case of a compound CS in which one of the elements is redundant and like a preexposed stimulus has no motivational significance. Specifically, in Stage 2 of the blocking paradigm both elements of the LT compound predict the occurrence of the UCS. Due to prior conditioning of the tone in stage 1 , however, the light serves as a redundant cue. Thus, since the light gives no new information regarding the UCS, it should be tuned out much in the same way a preexposed stimulus is. The data from animals in Groups C-BLO and N-BLO indicate this to be the case for cortical lesioned and normal 
rabbits. Specifically, both cortical and normal animals (Groups $\mathrm{C}-\mathrm{BLO}$ and $\mathrm{N}-\mathrm{BLO}$ ) given tone conditioning during Stage 1 exhibited significantly less conditioning to the light in Stage 2 than sit controls (Groups C-SIT and N-SIT). This is evidenced by significantly lower ratios for animals in the blocking groups. Comparison of the data from groups H-BLO and H-SIT, however, indicates that the blocking effect was not present in hippocampal lesioned animals. This suggests that in hippocampal rabbits the redundant light was not tuned out even though it had no motivational significance.

The data on tone and light + tone acquisition lend little support to the idea that the deficiency in blocking shown by hippocampals was due to an increased asymptotic value of the UCS $(\lambda)$ as the Rescorla-Wagner Model would demand in order to account for the blocking data. While examination of the tone acquisition curves (Figure 3) for hippocampals, corticals, and normals suggests that hippocampals conditioned at a slightly faster rate than corticals, analysis of these data indicated that these differences did not approach statistical significance. In addition, the depressed tone acquisition curve for cortical lesioned rabbits is largely attributable to one rabbit, $C-4$, who did not give a CR until Block 4 of Day 2. If not for the retarded acquisition of this rabbit, acquisition curves for corticals would be similar to those for hippocampals and normals with at least $94 \%$ conditioned responding from Block 3 of Day 1 on. 
The acquisition data from LT conditioning lend further support to the idea that hippocampal lesions did not elevate $\lambda$. Once again no reliable differences were found in either the rate of conditioning of the $C R$ or the total number of CRs emitted. In contrast to the data on tone acquisition, however, examination of the LT acquisition curves suggests that corticals and not hippocampals showed slightly faster conditioning although not significantly so.

Finally, the data on extinction may also be taken as evidence that $\lambda$ was not affected. If hippocampal lesions had raised the asymptotic value of the UCS, the associative value of the CS would also have been raised, and this should have produced more responding for hippocampals during extinction. This was not the case. In fact, hippocampals gave fewer responses, although not significantly so, than either corticals or normals.

The finding that hippocampal rabbits did not condition faster than controls is consistent with previous data from our laboratory (cf., Solomon \& Moore, 1975), but inconsisterit with the only other published study which examined the effects of hippocampectomy on conditioning of the rabbit's NMR (Schmaltz \& Theios, 1972). Specifically, Solomon and Moore found no differences in the rate of acquisition of the CR in hippocampals, corticals, and normals to a $76 \mathrm{~dB}, 1200$ Hz tone and a $2-m A$ shock UCS. Schmaltz and Theios, in contrast, reported faster conditioning in hippocampal lesioned 
rabbits than in cortical or normal controls. Their study, however, employed a substantially more salient CS (92 dB, $2000 \mathrm{~Hz}$ tone) and a stronger UCS (300 vac shock). Several empirical investigations (cf., Jarrard, 1973) have indicated that although hippocampal lesioned animals do not overreact to moderate stimuli, they do overreact to stimuli that are well above threshold. Thus the possibility exists that in the Schmaltz and Theios study the enhanced conditioning found in hippocampals was due to the relatively strong CS and UCS employed.

The finding that animals in the blocking groups gave more CRs during extinction than the sit controls agrees with Marchant and Moore's (1973) investigation of blocking in the rabbit NMR preparation. In their experiment, in which a light was used to block a tone, animals in the blocking group gave more CRs to light than those in the sit control groups. The authors attributed this difference to the greater number of conditioning trials to light in the blocking groups. Similarly, in the present experiment animals in the blocking groups received 800 trials in which the tone served as the CS, whether alone or in compound with the light, while animals in the control condition received only 500 such pairings. Thus the greater number of responses in extinction by animals in the blocking groups is probably due to the greater number of CS-UCS pairings during acquisition. 


\section{EXPERIMENT 2}

A number of theoretical reviews (e.g., Douglas, 1967; Kimble, 1968) and numerous experiments have expoused the view that the hippocampus is essential to conditioned inhibition (CI). Kimble has gone so far as to say that: "... the mammalian hippocampus, in coordination with the mesencephalic and diencephalic arousal system, is important in the brain processes operative in those behavioral situations in which Pavlovian conditioned inhibition is assumed to occur" (Kimble, 1967, p. 293); and Douglas concludes: "...the hippocampus is the site or organ of [Pavlovian] internal inhibition" (Douglas, 1967, p. 435).

The literature is replete with experiments which have purported to test this idea (see Altman, Brunner \& Bayer, 1973; Iziquierdo, 1975; O'Keefe \& Nadel, 1974, for the most recent reviews). These investigations have employed behavioral tasks ranging from successive discrimination in a $Y$ maze to two-way active avoidance learning; yet, incredible as it may appear, not one has asked the most pertinent question: What is the role of the hippocampus in Pavlovian conditioned inhibition? The purpose of the present experiment was to answer just that question.

Definition and Tests of Conditioned Inhibition

Hearst (1972) and Rescorla (1969) have defined conditioned inhibition while also presenting the operations necessary to produce and test this phenomenon. By way of 
definition Hearst and Rescorla agree upon the following points: (a) a stimulus is endowed with conditioned inhibitory properties as a result of past experience or conditioning, and $(b)$ as a result of this experience the stimulus becomes capable of reducing (inhibiting) some ongoing behavior which is attributed to excitation (or as Hearst puts it: "...develops the capacity to decrease the performance below the level occurring when the stimulus is absent.").

The operations necessary to produce a Pavlovian conditioned inhibitor are somewhat complex. Hearst and Rescorla agree that a stimulus will take on inhibitory properties when it is negatively correlated with a UCS. There are a number of behavioral paradigms which conform to this definition (see Rescorla, 1969, for a review). The most reliable way to produce CI, however, was initially described by Pavlov (1927). In this procedure, a CR is first conditioned to two separate and distinct stimuli: $\mathrm{CS}_{1}$ and $\mathrm{CS}_{2} \cdot$ This is followed by discrimination training in which $\mathrm{CS}_{1}$ is presented alone and always followed by the UCS (reinforced), while a compound consisting of $\mathrm{CS}_{1}$ and a third CS, $\mathrm{CS}_{3}$ is presented but never reinforced. In this way the animal gradually forms the appropriate discrimination: responding to $\mathrm{CS}_{1}$ and not responding to the compound of $\mathrm{CS}_{1}+\mathrm{CS}_{3}$. Since in this situation $\mathrm{CS}_{3}$ is negatively correlated with the UCS, it is expected to take on the properties of a conditioned inhibitor. 
The mere formation of the discrimination, however, is not a sufficient reason for concluding that $\mathrm{CS}_{3}$ has become a conditioned inhibitor. Rather, two specific testing procedures are required to make this decision. As mentioned earlier, a conditioned inhibitor must be capable of reducina some ongoing behavior which is generated by excitatory processes. To test for this, a combined cue summation test is employed. This consists of presenting the suspected innibitory stimulus $\left(\mathrm{CS}_{3}\right)$ together with a known excitatory stimulus (in this situation $\mathrm{CS}_{2}$ ) and assessing the suppression of the CR relative to appropriate controls. If, in fact, $\mathrm{CS}_{3}$ is inhibitory it is expected that: (a) conditioned responding to $\mathrm{CS}_{2}+\mathrm{CS}_{3}$ would be less than that to $\mathrm{CS}_{2}$ alone, and (b) that this difference would exceed that of a control group which experiences $\mathrm{CS}_{3}$ for the first time in summation test (i.e., a control for external inhibition).

While the presence of an inhibitory summation effect is a necessary condition for concluding that a conditioned inhibitor is present, it is not sufficient. For example, it is possible, albeit not likely, that prior association of $\mathrm{CS}_{3}$ with nonreinforcement causes the subject to attend to the stimulus so intently that when it is put in compound with an excitatory CS it causes the organism to shift attention away from the excitor and thus precludes the possibility of a $\mathrm{CR}$. One way to test for this possibility is to include 
the retardation-of-learning test. Here the suspect inhibitor is presented and reinforced. If $\mathrm{CS}_{3}$ is truly inhibitory development of the $C R$ should be retarded compared to a control group which experiences $\mathrm{CS}_{3}$ for the first time during retardation testing. If, however, $\mathrm{CS}_{3}$ merely mimics a conditioned inhibitor by attracting the animals attention away from the excitatory CS during summation test, facilitated acquisition relative to controls is expected. The assumption here is that if an organism pays more attention to a stimulus, conditioning will proceed at a faster rate.

Thus it appears that an inhibitory summation effect as well as the retardation-of-learning effect are necessary to conclude that a conditioned inhibitor is present. The possibility exists, however, that one of these effects may exist without the other. Table 3 summarizes the conclusions to be drawn from the combined use of these two assessment procedures.

Empirical Investigations of Conditioned Inhibition

Several empirical investigations have employed the Pavlovian procedure to form a conditioned inhibitor and subsequently tested for CI using the summation and retardation tests.

Marchant, Mis, and Moore (1972), working in the rabbit NMR preparation, trained their subjects to discriminate between a light $(\mathrm{CS}+)$ and a light plus tone compound (CS-). Next a summation test was conducted in which the tone was paired 
TABLE 3

POSSIBLE INTERPRE'TATIONS OF EXPERIMENTS WHICH

EMPLOY BOTH SUMMATION AND RETARDATION TESTS

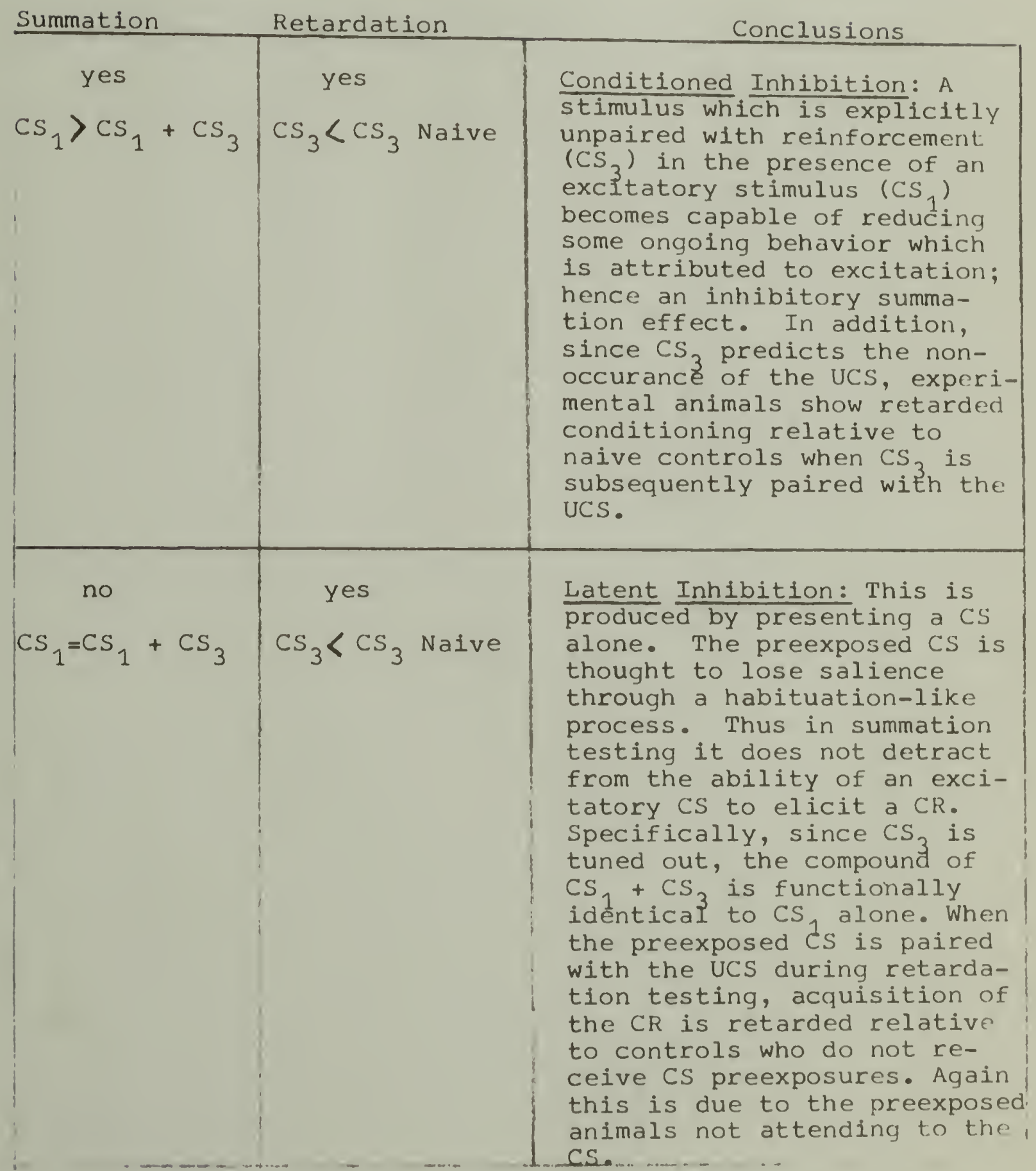


TABLE 3 (continued)

\begin{tabular}{|c|c|c|}
\hline Summation & Retardation & Conclusions \\
\hline $\begin{array}{c}\text { yes } \\
\mathrm{CS}_{1}>\mathrm{CS}_{1}+\mathrm{CS}_{3}\end{array}$ & $\begin{array}{c}\text { no } \\
\mathrm{CS}_{3}>\mathrm{CS}_{3} \text { Naive }\end{array}$ & $\begin{array}{l}\text { External Inhibition: CS } \\
\text { does not become inhibitory } \\
\text { but merely distracts the } \\
\text { organisms attention during } \\
\text { summation test. This is es- } \\
\text { pecially prevalent when CS } 3 \\
\text { is very salient or novel. } \\
\text { Due to this distraction it } \\
\text { does distract from the abil- } \\
\text { ity of CS to yield a CR; } \\
\text { hence an Inhibitory summa- } \\
\text { tion effect. Since, however, } \\
\text { the animal is paying more } \\
\text { attention to CS than a naive } \\
\text { animal, the opposite of a } \\
\text { retardation effect is found: } \\
\text { the animal given CI train- } \\
\text { ing conditions faster than } \\
\text { the naive control. }\end{array}$ \\
\hline $\mathrm{CS}_{1}<\mathrm{Cs} S_{1}+C S_{3}$ & $\begin{array}{c}\text { no } \\
\mathrm{CS}_{3}>\mathrm{CS}_{3} \text { Naive }\end{array}$ & $\begin{array}{l}\text { Conditioned Excitation: This } \\
\text { is brought about by pairing } \\
\text { a CS with a UCS--the exact } \\
\text { opposite of CI. This leads } \\
\text { to an excitatory summation } \\
\text { effect since both CS and CS } 3 \\
\text { are excitatory. It also } \\
\text { leads to faster conditioning } \\
\text { for the experimental animal } \\
\text { than a naive control in re- } \\
\text { tardation testing since CS } \\
\text { has received prior pairings } \\
\text { with the UCS. }\end{array}$ \\
\hline
\end{tabular}


with an excitatory noise. The results indicated that the tone detracted from the ability of the noise to elicit a CR. Furthermore, when the tone was paired with the eye shock UCS during retardation testing, acquisition of the CR was deterred. Other researchers working in the rabbit NMR and eyelid preparations have reported similar results (Marchant \& Moore, 1974; Rescorla \& Wagner, 1972).

Summation and retardation tests have also been used following Pavlovian discrimination training in the CER preparation, although not in the same experiment. Zimmer-Hart and Rescorla (1974) demonstrated an inhibitory summation effect following training in which a clicker served as the CSt and a compound consisting of the clicker and a light served as the CS-. In an experiment employing a similar discrimination procedure (Rescorla, 1971) a retardation effect was produced when the light was subsequently paired with the shock UCS.

Recent investigations of CI have demonstrated that stimuli other than lights and tones can also serve as conditioned inhibitors. For example, Tauklis and Revusky (1975) demonstrated that CI can be produced with odor serving as the inhibitory CS, and Moore et al., (1973) reported that electrical stimulation of the brain can serve as a conditioned inhibitor.

The Hippocampus and Conditioned Inhibition

The most direct evaluation of the role of the hippocampus 
in conditioned inhibition to date was reported by Micco and Schwartz (1971). In this experiment, rats were trained to run in a wheel to avoid an unsignalled shock (Sidman avoidance). This was followed by off the baseline Pavlovian fear conditioning in which a CS+ (tone) was always followed by footshock while a CS- (light) never was. Finally, a test was conducted in which rats were once again placed in the running wheel and the CS+ and CS- were individually presented. The results indicated that normal animals increased running speed in the presence of the CS+ and decreased it in the presence of the CS-. Animals with hippocampal lesions also showed increased responding in the presence of the tone but no decrement in running during CS-presentations. The authors concluded that the decrement in responding to the CSin normal animals was due to conditioned inhibition and the failure to find this effect in hippocampectomized rats was due to a deficit in CI.

The conclusion by Micco and Schwartz that the hippocampus is critical to conditioned inhibition remains questionable, however, since the procedures they used to evaluate the presence of a conditioned inhibitor differ substantially from those suggested by Rescorla (1969) and Hearst (1972). In the Micco and Schwartz study "summation testing" consisted of superimposing the suspected inhibitor (CS-) on a baseline of responding and inferring inhibition from a decrement in response rate. Whether this procedure constitutes a valid 
summation test has been seriously questioned in a recent experiment by Reberg (1972). Reberg reported that a stimulus which appeared excitatory by virtue of a testing procedure similar to that of Micco and Schwartz, was actually shown to be inhibitory when a combined cue summation test was conducted. Whether the Micco and Schwartz procedure produced a conditioned inhibitor in normal animals is questionable, thereby rendering the data on hippocampal animals difficult to interpret. Even if the summation test employed by Micco and Schwartz was valid, the second test of CI, the retardation test, was still lacking.

The failure to include the retardation test brings about additional problems in interpretation. For example, in the Micco and Schwartz procedure three possible outcomes of nonreinforcement to light are possible: (a) it may become a conditioned inhibitor, (b) it may attract more than its share of attention and thereby act as an external inhibitor, or (c) it may be tuned out (ignored) as in the case of a latent inhibitor. In the case of normal animals the third possibility, latent inhibition, may be ruled out. Since the CSattenuates wheel running; that is, it has an effect on ongoing behavior, it must have been attended to. To distinguish between a conditioned and external inhibitor in the absence of a retardation test, however, is difficult, if not impossible. Specifically, the failure to find an inhibitory summation 
effect in hippocampectomized animals is subject to two interpretations: a reduction or disruption of conditioned inhibition or a reduction or disruption of external inhibition. While Micco and Schwartz interpreted their results as supporting the former, there is substantial evidence to support the idea that hippocampal lesions lead to an increased resistance in external inhibition. A number of studies have shown that hippocampectomized animals are less easily distracted when engaged in goal directed behavior (e.g., Hendrickson, Kimble, \& Kimble, 1969; Raphelson, Isaacson, \& Douglas, 1965). This being the case, it is possible that the "inhibitory summation effect" found in normal animals in the Micco and Schwartz experiment was due to external inhibition and the failure to find this effect in hippocampectomized rats was the result of a decrement in external and not conditioned inhibition. The failure to include the retardation test makes it impossible to rule out this possibility.

Thus, the issue of what role, if any, the hippocampus plays in the formation of a Pavlovian conditioned inhibitor remains unresolved if not untested. The purpose of the present experiment was to evaluate the role of the dorsal hippocampus of the rabbit in the Pavlovian conditioned inhibition paradigm. In this study a conditioned inhibitor was formed via the method first described by Pavlov (1927). 
Since previous work in our laboratory (e.g., Marchant \& Moore, 1974) has shown that this procedure reliably produces both a summation and retardation effect, it is reasonably certain that it produces a reliable conditioned inhibitor. To determine the presence of a conditioned inhibitor, the present experiment employed two criteria: (a) discrimination between $C S_{1}$ and $C S_{1}+C S_{2}$, and (b) the retardation-of-learning test.

Although the pervading thought in the literature is that the hippocampus is essential to Pavlovian conditioned inhibition, more careful scrutiny of the operations necessary to produce this phenomenon lead to a somewhat different expectation. In the conditioned inhibition paradigm the animal must discriminate between $C S_{1}$ and $C S_{1}+\mathrm{CS}_{2}$. In order to do this the animal must attend to $\mathrm{CS}_{2}$; failure to do this results in failure to discriminate. If the assumption is correct that the hippocampus is responsible for tuning out stimuli not associated with reinforcement, (in this case $\mathrm{CS}_{2}$ since it predicts the nonoccurrence of the UCS), something the animal clearly does not want to do in this case, then hippocampal lesions should certainly not hinder, and perhaps may even facilitate the formation of a conditioned inhibitor. Relationship of Conditioned Inhibition to Blocking and Latent Inhibition

Earlier work in the rabbit NMR preparation has shown that latent inhibition is greatly disrupted by hippocampal 
lesions (Solomon \& Moore, 1975). To explain these data the authors concluded that the hippocampus is responsible for tuning out stimuli which have no motivational significance. In the first experiment of this study we demonstrated that hippocampectomy disrupts blocking. In the blocking procedure the animal may cease attending to a redundant cue. This redundant cue, like a latent inhibitor, does not in itself predict reinforcement. Thus, it appears that the hippocampus governs the blocking process much in the same way that it regulates latent inhibition: serving as a nonreinforcement register and assuring that stimuli which have no motivational significance are not attended to. In the conditioned inhibition paradigm, however, the situation is somewhat different. As in latent inhibition and blocking, a stimulus exists that does not predict the occurrence of the UCS, but unlike a preexposed or blocked CS, if the animal tunes out this stimulus it cannot behave appropriately; that is, it cannot make the required discrimination. Thus, in conditioned inhibition, since normals do not tune out the nonreinforced stimulus, it was expected that hippocampal lesions would not disrupt the formation of a conditioned inhibitor.

\section{Method}

\section{Animals}

The animals for this experiment were 27 experimentally naive male and female New Zealand white rabbits (Oryctolaqus 
cuniculus) weighing between 2.8 and $3.2 \mathrm{~kg}$ at the time of surgery. Each rabbit was randomly assigned to either the hippocampal $(n=9)$, cortical $(n=9)$ or normal $(n=9)$ condition. Animals were individually housed and maintained on food and water ad libitum.

Apparatus and Surgery

The apparatus and surgical procedures were the same as in Experiment 1.

\section{Procedure}

Following suturing of the right NM all animals were habituated to the restraint of the apparatus for 50 minutes (Day 1). On days $2-15 \frac{1}{2}$ all animals underwent discrimination training. Each day consisted of 50 light presentations (6.0 vdc) followed by a 2-mA UCS interspersed with 50 light plus tone $(86 \mathrm{db}, 1200 \mathrm{~Hz})$ presentations which were never followed by the UCS ( $25 \mathrm{~L}$ and $25 \mathrm{LT}$ trials on Day 16). For the last 50 trials on Day 16 and for 100 trials on Days 17 and 18 , retardation testing was conducted. This consisted of pairing the tone with the eye shock UCS in a conditioning procedure. Shortly after the completion of retardation testing operated animals were sacrificed by a sodium pentobarbitol overdose, perfused, and their brains subjected to the histological procedures described in Experiment 1.

\section{Results}

Following Day 13 of differentiation one animal in 
the cortical group $(c-26)$ died as a result of a broken back. Thus the data for Days 14 and 15 of differentiation and for all 3 days of retardation testing are based on the remaining eight cortical lesioned animals. To facilitate data analysis, differentiation scores for C-26 on Days 14 and 15 were projected by taking the average of the three prior days ${ }^{1}$. Similarly, retardation data from animal C-26 was estimated by taking the mean of the remaining eight cortical animals. Differentiation

Figure 5 depicts the mean percentage conditioned responding to the light $\left(C_{+}\right)$and the light plus tone (CS-) over the 15 days of discrimination training for hippocampals, corticals, and normals. Examination of the figure indicates that each group gradually acquired the discrimination over the training period. More important, however, is the observation that the difference in responding to the $\mathrm{CS}+$ and the CS- did not vary as a function of lesion type. An analysis of variance which treated lesion type as a between groups variable, and days and trial type as within groups variables confirmed these observations. Specifically, a significant trial-type effect was found indicating greater overall responding to the CSt than to the CS- $(\underline{F}=29.06, \underline{d f}=1 / 24, \underline{p}(.001)$. In addition, these differences in responding increased

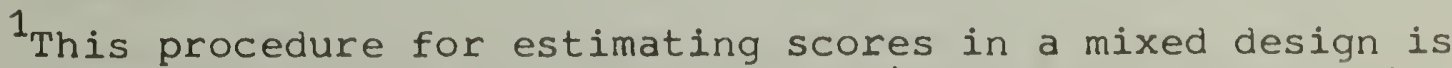
somewhat unusual (cf., Myers, 1972); however, examination of the differentiation data indicated that the scores on Days 11,12 , and 13 were the best predictors of the scores on Days 14 and 15 . 
FACE PAGE FOR FIGURE 5

Figure 5. Left Panels: Mean percent conditioned responding to the light $(\mathrm{CS}+)$ and light plus tone $\left(\mathrm{CS}_{-}\right)$for hippocampals, corticals, and normals over the 15 days of differentiation training. Right Panel: Mean percent conditioned responding to the tone for hippocampals, corticals, and normals over the three days of retardation testing. 

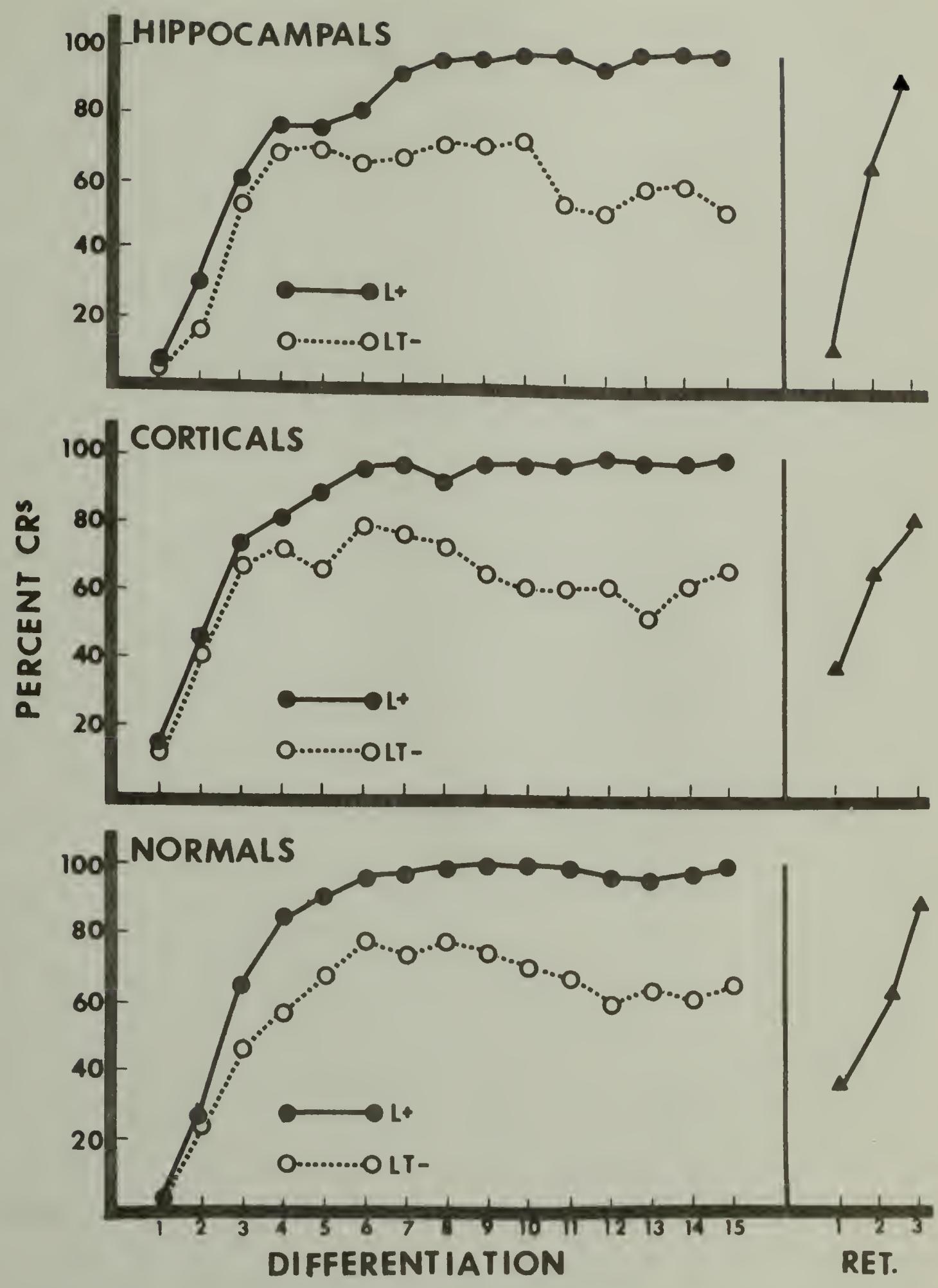
significantly as discrimination training progressed. This is evidenced by a significant Trial Type $x$ Days interaction $(\underline{F}=12.58, \underline{d f}=14 / 336, \underline{p}<.001) . \quad$ Of greatest significance, however, is the failure to find a reliable Lesion X Trial Type interaction $(\underline{F}=\langle 1, \underline{d f}=2 / 24, \underline{p}\rangle .05)$ confirming the observation that the amount of responding to either the CS+ or the CS- was not affected by hippocampal or cortical ablation.

Retardation

The right hand panels of Figure 5 show acquisition curves for the tone during the three days of retardation testing.

To determine whether lesion type had any effect on either the total number of CRs emitted during retardation testing or the rate of acquisition of the CR, an ANOVA was performed in which lesion type served as a between groups variable and days as a within groups variable. Results of the analysis indicated a significant days effect $(\underline{F}=18.95, \underline{\mathrm{d} f}=2 / 48$, $\mathrm{p}(.001)$, but no reliable differences as a function of lesion type $(F=\langle 1, \underline{d f}=2 / 24, p\rangle .05)$ or the interaction of the two variables $(\underline{F}=1.01, \underline{\mathrm{d} f}=4 / 48, \underline{\mathrm{p}}) .05)$.

Inspection of Figure 5 indicates that the significant days main effect resulted from an increase in conditioned responding as the number of CS-UCS pairings increased. More important, however, was the failure to find a significant 
lesion main effect. This suggests that neither cortical or hippocampal lesions affected the total number of CRs emitted during acquisition of a conditioned response to a stimulus which had undergone inhibitory training. Finally, although hippocampals gave fewer conditioned responses on Day 1 than corticals or normals, and somewhat more CRs on Day 3, these differences did not prove to be reliable as evidenced by the failure to find a significant Lesion $X$ Days interaction. This indicates that, as in the case of the total number of CRs emitted, the rate of acquisition of the $C R$ does not vary as a function of lesion type.

As a second index of responding during retardation testing, the number of trials to reach criterion of 5 or 10 consecutive CRs was computed for the three experimental groups. Table 4 shows these figures. As in the case of the total number of CRs emitted, analysis of these data suggests that the tone acquires equal inhibitory strength for hippocampals, corticals, and normals. A one-way ANOVA on the number of trials to reach 5 consecutive CRs yielded no reliable differences between groups $(\underline{F}=\langle 1, \underline{d f}=2 / 24, \underline{p}\rangle .05)$ as did an ANOVA on the number of trials to reach 10 consecutive CRs $(\underline{F}=\langle 1, \underline{d f}=2 / 24, \underline{p}\rangle .05)$.

\section{Discussion}

The Hippocampus and Conditioned Inhibition

The major finding of this experiment, that hippocampectomy did not affect the formation of a conditioned inhibitor, 
TABLE 4

MEAN NUMBER OF TRIALS TO CRITERION

\begin{tabular}{|c|c|c|c|}
\hline 5 Consecutive CRs & 88.2 & 90.2 & 82.0 \\
\hline 10 Consecutive CRs & 103.1 & 102.9 & 93.8 \\
\hline
\end{tabular}


is in direct contrast with a number of other reports which have implicated the hippocampus in conditioned inhibition (e.g., Douglas, 1967; Kimble, 1968; Micco \& Schwartz, 1971). During the differentiation stage of this experiment, hippocampals, corticals, and normals all acquired the discrimination at approximately the same rate. In addition, all animals reached about the same level of discrimination by the end of Day 15. This finding, at first examination, appears at odds with prior work which indicated that hippocampals were not able to tune out and withhold responding to a nonreinforced stimulus (cf., Douglas, 1972). Kimble (1963) found hippocampectomized rats to be deficient in learning a successive discrimination in a $Y$ maze (e.g., turns to the right reinforced when both arms are black, turns to the left reinforced when both arms are white), although they had no difficulty in the acquisition of a simultaneous discrimination (one arm black, one arm white). To account for the data in the successive discrimination task, which is analagous to Pavlovian differential conditioning since only one stimulus is presented at a time, Kimble argued that the animal could not inhibit responding to the $\mathrm{S}$ - and therefore could not form the discrimination. In the simultaneous procedure, however, since both the $S+$ and $S$ - are present on each trial, the animal can learn the discrimination strictly by responding to the S+. The possibility exists, then, that in the simultaneous procedure normals tune out the S- through an 
habituation-like process; consequently, the animal ceases to respond to it. In support of this argument, Moore (1974) presented data to suggest that in a differential conditioning paradigm (light reinforced, tone nonreinforced), the CScan undergo a loss of salience as long as the two stimuli are presented in different sensory modalities. Since prior work (Ackil et al., 1969; Solomon \& Moore, 1975, Experiment 1 of the present study) has indicated that hippocampal lesioned animals have difficulty in tuning out a CS-, it is not surprising that they have difficulty in acquiring a successive discrimination. These data also suggest that hippocampals would be deficient in acquisition of differential classical conditioning, although this experiment has yet to be done. What might seem surprising, at least in terms of prior theoretical accounts, is the finding that hippocampals have no difficulty in learning a successive discrimination in the conditioned inhibition paradigm. The CI paradigm, however, represents a special form of differential conditioning, and a more careful examination of the operations necessary to produce this type of discrimination suggests that the findings of the present experiment are consistent with the earlier work on successive discrimination. Specifically, in the successive discrimination or the differential conditioning task tuning out the CS- enhances the formation of the discrimination. In the CI task, however, tuning out the CS- (tone), that is, the stimulus which uniquely predicts the nonoccurence of the 
UCS, would make the discrimination impossible since the light and light plus tone would then be functionally identical. Clearly, normal animals do not do this (e.g., Marchant et al., 1972). As the tone is not tuned out in normal animals, there is no reason to believe that the hippocampus, or any other brain structure, is involved in this process. Simply put, there is no reason to postulate neural mechanisms for a process which does not occur. It follows then that removal of the hippocampus should not affect the discrimination between the light and the light plus tone compound in the CI paradigm. The results of the present study are consistent with this prediction.

It is interesting to note that in the rabbit the formation of a conditioned inhibitor is a much more difficult task than simple differential conditioning (cf., Moore, 1972; Marchant \& Moore, 1974). One possible explanation for the relative difficulty in CI is that the animal actually attempts to tune out the tone early in training. Although there is presently no behavioral data which reflects upon this argument, the data from hippocampals suggests that this is not the case. Specifically, given the possibility that the tuning-out process does go on early in training and the hypothes is that hippocampectomy disrupts this process, it is reasonable to assume that hippocampal lesions might actually facilitate the formation of conditioned inhibition. 
No such facilitation was found in the present experiment. Although hippocampals, corticals, and normals did not differ during the differentiation stage of this experiment, this in itself is not sufficient evidence to conclude that they can form a conditioned inhibitor. For example, it is possible that corticals and normals did not respond during CS- trials as a result of the tone becoming inhibitory. Hippocampals, alternately, may not have responded due to the compound as a result of the tone distracting the animals attention away from the excitatory light, e.g., external as opposed to conditioned inhibition. (In a similar situation Solomon and Moore, 1975, reported a tendency for hippocampals to be more easily distracted.) The retardation-of-conditioning test was included to test this possibility. If, in fact, the tone did not become inhibitory in hippocampals, but merely distracted the rabbit's attention from the excitatory light, hippocampals should have conditioned faster to the tone than corticals or normals when it was paired with the eye shock UCS during retardation testing. This was not the case. Hippocampals, corticals, and normals did not differ in the total number of CRs emitted during testing nor in the number of trials needed to reach a criterion of 5 or 10 consecutive CRs. In addition, the rate of acquisition of the CR for animals in the present experiment is considerably slower than that of animals which do not receive inhibitory training 
during the differentiation phase (cf., Marchant \& Moore, 1974). Thus, the results of both the differentiation and retardation phases of the present experiment suggest that the hippocampus is not critical to the conditioned inhibition process.

The Cortex and Conditioned Inhibition

In addition to the results from hippocampal animals, the data which show that cortical lesions do not disrupt conditioned inhibition are also of interest. Pavlov (1927) hypothesized that the cortex was the seat of internal inhibition. In regard to this he noted that dogs with partial neocortical ablation exhibited an augmentation of the $C R$ and a corresponding weakening of internal inhibition (Pavlov, 1927, p. 324). More recently, however, the role of the neocortex has been examined in the rabbit NMR preparation with somewhat different results. Oakley and Russell (1972) reported that acquisition of the $C R$ to a tone CS was not altered in hemi- or decorticate rabbits. Similarly, Norman et al. (1974) found no decrement in conditioned responding in decorticate cats. The results from animals with neocortical lesions in this experiment and Experiment 1 are consistent with these reports.

In an attempt to investigate the role of the neocortex in inhibitory control, Oakley and Russell (1974) examined the effects of partial or total neocortical ablation on differential classical conditioning (light reinforced, tone 
nonreinforced). They found no difference in the rate of acquisition of the discrimination suggesting that the cortex is not critical to the withholding of the NMR in the presence of a CS-. In addition, Norman et al. (1974) indicated that decorticate cats have no difficulty in acquiring a tone frequency discrimination. A study by Eichenbaum et al. (1974), however, suggested that an understanding of the role of the neocortex in differential conditioning may not be quite this simple. Specifically, they reported that lesions of the frontal cortex in rabbits greatly disrupted the reacquisition of a tone reinforced (90 dB), tone nonreinforced (70 dB) discrimination. Similarly, several other researchers have found that rabbits with frontal cortical lesions are deficient in the acquisition (Balinska, 1966) and retention (Balinska, Brutkowski, \& Stefanicka, 1966) of a cued go-no go discrimination. This effect, however, is not readily observed in the cat (Zielinski \& Czarkowska, 1973, 1974). Thus, the role of the neocortex in differential conditioning remains somewhat unclear and what role, if any, the cortex plays in conditioned inhibition remains an empirical question. The data from the present study, however, suggest that relatively small neocortical lesions do not disrupt the formation of a conditioned inhibitor.

Functional Specificity

The findings of the present experiment are in contrast to the only other published study which attempted to directly 
evaluate the role of the hippocampus in conditioned inhibition (Micco \& Schwartz, 1972). One possible explanation for this discrepancy resides in the different methods used to produce and test for a conditioned inhibitor. These arguments have been presented in the introduction to this experiment. A second possibility, however, lies in the locus of the lesion. In the present study the majority of the hippocampal damage was limited to the dorsal portions of the structure. Micco and Schwartz, in contrast, induced electrolytic lesions and were thus able to destroy both dorsal and ventral hippocampus. There have been several recent studies, both anatomical and behavioral, which suggest that there may be functional specificity along the dorsal-ventral dimension within hippocampus. Employing electrophysiological and anatomical techniques, a number of experimenters have indicated that the ventral hippocampus, by way of the lateral fimbria, projects to the lateral septal nucleus while the dorsal hippocampus, via the medial fimbria, projects to the medial septal nucleus (Anderson, Bland \& Dudar, 1973; Edinger, Siegel \& Troiano, 1973; Siegel \& Tassoni, 1971). In addition, Hjorth-Simonsen (1971) and Siegel and Tassoni (1971) reported efferents from ventral hippocampus to subicular and entorhinal cortex. Fibers to these areas originating in dorsal hippocampus have not as yet been identified.

Data from behavioral studies also suggest that the 
hippocampus is not a functionally homogeneous structure. Liss (1968) found that two-way active avoidance (AA), a behavior greatly enhanced by hippocampal destruction (e.g., Olton \& Isaacson, 1968), was also augmented by lesions limited to the ventral hippocampus or lateral fornix. Van Hoesen et al. (1972) reported enhanced acquisition of AA following sectioning of the fimbria-fornix complex but not following entorhinal damage. Finally, Rabe and Haddad (1969) found facilitated AA with total hippocampal lesions but not with those limited to the dorsal or ventral portions.

Complex maze learning, a behavior greatly disrupted by hippocampectomy (e.g., Jackson \& Strong, 1969), has also been examined in animals with partial hippocampal damage. Gross, Chorover, and Cohen (1965) reported that ventral lesions impaired acquisition of a Hebb-Williams maze while dorsal lesions had no such effect. In direct opposition, Hughes (1965) found disruption of maze learning following dorsal but not ventral destruction.

Nadel (1968) reported that CER acquisition was retarded by both dorsal and ventral lesions, while the rate of habituation of an exploratory response was only decreased by ventral damage.

Stevens and Cowey (1973), in an extensive series of experiments, found that ventral lesioned animals were hampered in spatial probability learning, lever alternation, and 
spontaneous alternation, while dorsal lesioned rats only showed deficits in spontaneous alternation. Based on these data the authors concluded that the dorsal hippocampus was involved ir behavioral habituation while the ventral portions mediated hypothesis testing ( $\mathrm{e} \cdot \mathrm{g} \cdot$, the ability to shift strategies).

While the data from these studies do not uniquivocally delegate one function to the dorsal hippocampus and other functions to the ventral portion of the structure, they do suggest that the different portions control different types of behavior. Thus the possibility that the ventral hippocampus plays a role in CI, even though the dorsal hippocampus does not, remains an interesting and testable question.

\section{GENERAL DISCUSSION}

The major findings of the present study are: (1) dorsal hippocampal ablation eliminated blocking of a light by a tone in Kamin's two-stage paradigm, and (2) hippocampectomy did not affect the formation of a Pavlovian conditioned inhibitor. Taken together these findings support the Douglas (1972) model of the limbic system which states that the hippocampus is part of a neural system whose purpose is to assure that the organism does not attend to stimuli which have no motivational significance. More specifically, the Douglas model assumes that the hippocampus receives information that a potential CS has been received and whether it 
is followed by reinforcement. In the event that the CS is not reinforced, the hippocampus discharges downward and inhibits the midbrain areas involved in the reception of that stimulus.

Douglas' model is especially attractive for several reasons. First, it is capable of accounting for much of the behavior observed in animals with hippocampal lesions (cf., Douglas, 1972). Second, unlike prior theoretical statements on the role of the hippocampus in inhibition (e.g., Kimble, 1968), it specifies a mechanism whereby the hippocampus comes to exert an inhibitory influence over certain behaviors. Third, and perhaps most important, it presents a neural system which may control these behaviors, namely the hippocampal-midbrain system.

Possible Neural Mechanisms Involved in the Tuning-Out Process

There is a reasonable amount of data which supports the idea that the hippocampus, in conjunction with the midbrain arousal centers, governs the process whereby redundant or irrelevant stimuli lose control over behavior. Beginning with two elegant studies by Nauta (1956, 1958), several anatomical reports have indicated a direct relationship between the hippocampus and midbrain.

The primary hippocampal efferent, the fornix, splits into a pre- and postcommissural branch at the level of the anterior commissure. Fibers leaving the precommissural fornix enter the septum and then continue on to the midbrain via 
two separate paths. First, they may project via the stria medullaris to the medial habenular nucleus. From the habenula they continue in the fasciculus retroflexus to the interpeduncular nucleus or the dorsal tegmental nucleus of the central midbrain gray (Nauta, 1956, 1958; Valenstein \& Nauta, 1959). Alternatively, fibers may leave the septum and travel in the medial forebrain bundle, traversing the lateral hypothalamus, and terminating in several midbrain areas including the interpeduncular nucleus, the ventral tegmental area of Tsai, and the dorsal tegmental nucleus. The postcommissural fornix also projects to the midbrain. This path, however, turns ventralward prior to reaching the septum to synapse in the mammillary bodies which in turn send axons to the dorsal and ventral tegmental nuclei via the mammillotegmental tract (Guillery, 1956; Nauta, 1956).

To reciprocate these limbic-midbrain connections, Nauta (1958) has reported a midbrain-limbic path which originates in the central gray and projects to the hypothalamus. Other investigators have reported fibers which originate in the dorsal and ventral tegmental nuclei and project to the mammillary bodies, lateral hypothalamus, and medial septum (Guillery, 1956; Morest, 1961; Nauta \& Kypers, 1958). The projections from the septum to the hippocampus are, of course, well documented (e.g., Raisman, Cowan, \& Powell, 1965).

Behaviorally, there is evidence to suggest that many of the same effects found following hippocampal damage are 
also present after lesions of other structures in the limbicmidbrain system. Altman, Brunner, and Bayer (1973) and Fried (1972) have pointed out the behavioral similarities found following lesions of the septum and those of the hippocampus. Thomas (1971) compared lesions of the fornix and hippocampus and found that both impaired retention and relearning of a complex maze. Lesions of the fornix have also been shown to alter position reversal and spontaneous alternation (Green \& Stauff, 1974; Hirsch \& Segal, 1972). In addition Alvarez-Palaez (1973) reported that fimbria-fornix damage enhanced the acquisition of a two-way avoidance task. Olton and Isaacson (1968) reported similar results following hippocampal ablation.

Although comparatively little attention has been paid to the habenula, Van Hoesen et al. (1969) reported that lesions of both septum and habenula enhanced active avoidance and produced greater resistance to extinction. Thus it appears that disrupting the paths by which the hippocampus communicates with the midbrain reproduces many of the effects found after hippocampal destruction.

Several recent investigations have examined the role of the limbic-midbrain projection areas in the control of behavior. In general, these studies have indicated the disrupting midbrain areas which receive hippocampal input produce effects which are in many ways similar to those found following hippocampal destruction. 
Isaacson (1972) reviewed a series of studies which indicated that penicillin injected into hippocampus produced a disrupticin of active avoidance learning, the opposite effect of that found when the hippocampus is removed. Isaacson hypothesized that this effect was due to seizure discharges produced by the penicillin. Hamilton and Isaacson (1970) investigated the effects of penicillin placed directly irto various midbrain sites. The authors reported that the greatest disruption of active avoidance was found following application of penicillin into the ventral tegmental area. Interestingly, this is not only one of the primary limbic-midbrain areas, but also the site reported to receive the propagation of limbic seizures (Goodfellow \& Neimer, 1961).

Lewis and Shute (1967) and Shute and Lewis (1967) mapped both the ascending cholinergic system and the cholinergic reticular system. In general, their data show that fibers originating in the ventral tegmental area and ascending via the mammillary peduncle to the lateral hypothalamus are cholinergic. In addition, projections from the lateral hypothalamus to the septum, and from the septum to the hippocampus are also cholinergic. Given these findings it would appear that a blockade of the cholinergic system would mimic the effects of hippocampal lesions by functionally dissociating the hippocampus from the midbrain. There is substantial evidence to support this view. Carlton and his 
associates (see Carlton, 1968, for a review) for example, have shown that scopolamine disrupts habituation to a novel environment, an effect also found following hippocampectomy (cf., Jarrard, 1973). Similarly, Oliverio (1967) reported that systemic scopolamine injections discupted latent inhibition in a shuttle box. Once again, similar results were found in hippocampectomized rats (Ackil et al., 1969). Scopolamine injections have the same effect on two-way avoidance (Suits \& Isaacson, 1968) and spontaneous alternation (Douglas, 1966) as does hippocampal ablation. Racine and Kimble (1965) reported that hippocampal ablation disrupted delayed spatial alternation. White (1974) reported similar findings following systemic administration of either atropine. or scopolamine. Finally, Warburton (1972) found that atropine cannulated directly into ventral hippocampus disrupted acquisition of a go-no go discrimination in rats. Atropine applied directly to the ventral tegmental nucleus produced a similar effect (Warburton \& Russell, 1969).

Thus there appears to be a substantial literature that suggests that the hippocampus controls the tuning out of irrelevant stimuli by exerting an inhibitory effect on various portions of the midbrain. Most of this evidence, however, is indirect. To this point few studies have directly compared the effects of hippocampal damage with those following damage to various Iimbic-midbrain areas. The results of Experiment 1 
of the present investigation suggests that blocking is one behavior which is greatly disrupted by hippocampal lesions. Although it appears that the limbic-midbrain system is the logical candidate for the control of blocking, it remains an empirical question as to whether midbrain lesions or lesions of the various paths between the hippocampus and midbrain wculd produce a similar disruption.

Relationship of the Tuning-out Theory to Other Theories of Hippocampal Function

The present research supports the idea that the hippocampus is involved in inhibitory functions in the broadest sense of the term. Merely stating that a lesion produces a deficit in inhibition, however, may not be very useful in terms of understanding the functions of a particular neural structure or system. It is relatively easy to interpret post hoc ary lesion induced change in behavior in terms of a deficit in inhibition. The present study, however, goes one step further in attempting to specify the nature of the inhibitory deficit in terms of a failure to tune out irrelevant stimuli.

Other theories which have ascribed an inhibitory role to the hippocampus, however, have attempted to specify the deficit in somewhat different terms.

One early hypothesis, the perseveration hypothesis (see Douglas, 1967), simply stated that hippocampectomized animals tended to respond in a previously established manner even 
though it was no longer appropriate. This hypothesis can nicely explain the data which indicates that hippocampectomized rats exhibit more responding in extinction (e.g., Niki, 1965), or that they cannot switch from a CRF to a DRL schedule of reinforcement (e.g•, Clark \& Isaacson, 1965) even though they can learn the DRL if trained on this schedule from the outset (Schmaltz \& Isaacson, 1966). It can also account for the failure of hippocampectomized animals to show reversal learning (e.g., Olton, 1972). The perseveration hypothesis, however, has some difficulty handing data from Experiment 2 of the present study. In this experiment all animals initially showed a high level of responding to the CS-, but over the course of training cease to respond to this cue. The perseveration hypothesis provides no mechanism for this shift in behavior.

A refinement of the perseveration hypothesis, the idea that hippocampals do not have the ability to shift hypotheses, has recently been presented by Isaacson (1974). In support of this Isaacson and Kimble (1972) reported that hippocampectomized rats generated fewer hypotheses and maintained these for longer periods of time than controls while learning a successive discrimination. As in the case of the perseveration theory, however, Isaacson's theory has some difficulty in accounting for the data on conditioned inhibition. Still another offshoot of the inhibitory theory states 
that hippocampals perseverate only in situations which involve? spatial as opposed to visual cues (e.g•, Cohen, Laroache, \& Beharry, 1971; Sammuels, 1971). In regard to this, O'Keefe and Nadel (1974) have recently proposed a theory which states that the hippocampus subserves the function of a cognitive mapping system of the environment. Specifically, the authors proposed that the hippocampus represents a framework in which all stimuli that the animal attends to are represented. As the animal moves through its environment the hippocampus provides continual predictions as to what it will encounter. If one of these predictions is not verified, a "mismatch" is registered and the animal ceases (inhibits) its ongoing behavior and directs its attention toward the incongruity. This theory has received some support at both the behavioral and electrophysiological levels (see Nadel \& O'Keefe, 1974); but it is difficult to see how a spatial deficit could explain the data from the present experiments since in the NMR preparation the animal is totally restrained and stimuli are always presented in exactly the same place. The acquisition data from Experiments 1 and 2 are generally consistent with other accounts from the animal literature (cf., Douglas, 1967; Isaacson, 1972, 1974) in that they lend little support to the notion that the hippocampus is involved in memory. Since no deficit in acquisition of a CR to a tone CS (Experiment 1), a light CS (Experiment 2), or a compound consisting of both (Experiment 1 ) was observed in 
hippocampals, it is unlikely that these animals had any difficulty in remembering the relationship between the $C S$ and UCS over trials or days. These stimuli, however, may all be classified as excitatory and it is possible that hippocampal lesions do not disrupt all memories, but just those concerning stimuli which are not reinforced.

The results of Experiment 2 indicated a slight tendency for hippocampals to respond more to the nonreinforced light plus tone CS at the beginning of each day (first block of 20 trials) than at the end of the previous day (fifth block of 20 trials) when compared to corticals and normals. This effect was especially prevalent when hippocampals first started to discriminate between the CS+ and CS- (Days 7, 8, \& 9). An analysis of these data, however, indicated that the differences between the groups did not approach statistical significance. It is possible that the enhanced spontaneous recovery of responding to the CS- in hippocampals reflects a heightened state of emotionality rather than a memory deficit. We have observed that some hippocampal lesioned rabbits appear more emotional than cortical or normal controls. While this condition does not affect the excitatory conditioning process, it may well disrupt the more labile inhibitory process which is especially vulnerable when a conditioned inhibitor is first being formed. This heightened emotionality may cause hippocampals to take somewhat longer 
to adjust to the restraint of the apparatus at the beginning of each session, this leading to a temporary disruption of the inhibitory process.

Possible Nural Mechanisms Involved in Conditioned Inhibition The results of Experiment 2 indicated that dorsal hippocampals, corticals, and normals all formed a conditioned inhibitor at about the same rate. Since these data contradict the purvadiug thought in the literature by indicating that the hippocampus is not critical to the conditioned inhibition process, one important question becomes what neural. mechanisms or structures are critical to this behavior.

Mis (1975), in his doctoral dissertation, conducted a series of studies examining the role of various midbrain structures in the rabbit on pavlovian conditioned inhibition.

In one experiment he induced lesions in several midbrain sites and found that the greatest disruption of CI occurred Eollowing damage to the interstitial nucleus of Cajal, the mucleus of Darkschewitsch, and the parvocellular portion of the red nucleus. It is interesting that these portions of the midbrain are anterior to the limbic-midbrain projection areas. Thus it is possible that structures outside the 1 imbic system govern the process of conditioned inhibition. One such area may be the frontal cortex.

Leonard (1969) working in the rat, found evidence that the dorsomedial frontal cortex projects to a number of midbrain 
areas including the area immediately beneath the posterior commissure. Black and Myers (1962) reported a path in the monkey between the frontal cortex and the nucleus of Darkschewitsch. It may be no coincidence that it is precisely these midbrain areas that were critical to the formation of a conditioned inhibitor in Mis' study.

Several investigators have found deficits in behaviors thought to be under inhibitory control following ablation of the dorsomedial frontal cortex. For example, a recent study by Nonneman, Voight, and Kolb (1974) indicated that lesions of the dorsomedial frontal cortex led to deficits in spatial reversal, spatial probability, and DRL learning. Konorski (1972) reviewed a substantial body of literature which indicated that dorsomedial frontal cortex ablation in dogs led to deficits in go-no go discrimination tasks. Similarly, Eichenbaum et al. (1974) reported that total frontal ablation led to deficiencies in the retention of differential conditioning of the rabbit's NMR.

It appears, then, that the frontal cortex, like the hippocampus, has been implicated in the inhibitory process (see Brutkowski, 1965, for a review of the earlier literature). Furthermore, the anatomical evidence indicates that the dorsomedial frontal cortex sends efferents to the midbrain areas which seem to govern conditioned inhibition. A determination of what role, if any, the frontal cortex plays in conditioned 
inhibition however, must await further research.

In addition to the possibility that the frontal cortex is involved in conditioned inhibition, there also exists the possibility that the ventral hippocampus plays a role in this process. There is even some data to suggest that the two structures might actually work together in the control of certain behaviors. This is anatomically feasible since in both the rabbit (Adey, 1957) and monkey (Nauta, 1972) the frontal cortex projects to the juxtahippocampal cortex. At the behuvioral level, Nonneman et al. (1974) reported that total hippocampal ablation produced some of the effects found after frontal damage, while Campbell, Balantine, and Lynch (1971) reported data to suggest that the hippocampus may play a role in the recovery of function following frontal ablation. To this point, however, there are no studies which have directly compared the effects of ventral hippocampal and frontal lesions. 


\section{References}

Ackil, J.E., Mellgren, R.L., Halgren, C., and Frommer, G.P. Effects of CS preexposure on avoidance learning in rats with hippocampal lesions. Journal of Comparative and Physiological Psychology, 1969, 69, $\frac{1}{739-747 .}$

Adey, W.R. An experimental study of the hippocampal connections of the cingulate cortex in the rabbit. Brain, 1957, 74, 233-247.

Allen, W.F. Effect of ablating the frontal lobes, hippocampi, and occipito-parieto-temporal (excepting pyriform areas) lobes on positive and negative olfactory conditioned reflexes. American Journal of Physiology, 1910,128 ,
$754-771$.

Altman, J., Brunner, R.L., and Bayer, S.A. The hippocampus and behavioral maturation. Behavioral Biology, 1973, 8, 557-596.

Alvarez-Pelaez, R. Effects of fimbria-fornix lesion on avoidance conditioning in the rat. Physiology and Behavior, 1973, 11, 603-607.

Anderson, P., Bland, B.H. and Dudar, J.P. Organization of hippocampal output. Experimental Brain Research, 1973, $17,152-168$.

Bakal, C.W., Johnson, R.D., and Rescorla, R.A. The effect of change of US quality on the blocking effect. The Pavlovian Journal, 1974, 9, 97-103.

Balinska, H. Differentiation learning in rabbits with lesions of the frontal cortex or hypothalamus. Acta Biologica Experimentalis (Warsaw), 1966, 26, 259-266.

Balinska, H., Brutkowski, S., and Stefanicka, J. Frontohypothalamic control over food-reinforced conditioned reflex performance and differential inhibition in rabbits. Acta Biologica Experimentalis (Warsaw), 1966, $26,3-23$.

Black, P., and Myers, R.E. Connections of the occipital lobe in the monkey. Anatomical Record, 1962, 142, 216.

Blanchard, R.J., and Fial, R.A. Effects of limbic lesions on passive avoidance and reactivity to shock. Journal of Comparative Psychology, 1968, 66, 606-612. 
Brutkowski, S. Functions of the prefrontal cortex in animals. Physiological Reviews, $1965, \underline{45}, 721-746$.

Campball, B.A., Ballantine, P., and Lynch, G. Hippocampal control of behavioral arousal: Duration of lesion effects and possible interactions with recovery after frontal cortical damage. Experimental Neurology, 1971,
33, 159-170.

Carlton, P.L. Brain acetylcholine and inhibition. In: J. Tapp (Ed.), Reinforcement: Current Research and Theories. New York: Academic Press, 1968.

Clark, C.V.H., and Isaacson, R.L. Effect of bilateral hippocampal ablation on DRL performance. Journal of Comparative and Physiological Psychology, $1965,59, \frac{5}{13} 7-140$.

Cohen, J.S., Laroche, J.P., and Beharry, E. Response perseveration in the hippocampal lesioned rat. Psychonomic Science, $1971,23,221-223$.

Cragg, B.G. Afferent connections of the allocortex. Journal of Anatomy, 1965, 99, 339-357.

Dennis, W., and Sollenberger, R.T. Negative adaptation in maze exploration in rats. Journal of Comparative and Physiological Psychology, 1934, 18, $19 \overline{7-205 .}$

Douglas, R.J. Cues for spontaneous alternation. Journal of Comparative and Physiological Psychology, 1966, 62, $171-183$.

Douglas, R.J. The hippocampus and behavior. Psychological Bulletin, $1967,67,416-442$.

Douglas, R.J. Pavlovian conditioning and the brain. In: R.A. Boakes and M.S. Halliday (Eds.), Inhibition and Learning, New York: Academic Press, 1972.

Douglas, R.J., Barrett, T.W., Pribram, K.H., and Cerny, M.C. Limbic lesions and error reduction. Journal of Comparative and Physiological Psychology, $19 \overline{69,68}, \frac{63}{43}-441$.

Douglas, R.J., and Isaacson, R.L. Hippocampal lesions and activity. Psychonomic Science, 1964, 1, 187-188.

Douglas, R.J., and peterson, J.J. Is it true what they say about two-stage hippocampal lesions? Paper presented at the Western Psychclogical Association Meeting, Vancouver, B.C., 1969. 
Douglas, R.J., and Pribram, K.H. Learning and limbic lesions. Neuropsychologia, 1966, 4, 197-220.

Edinger, H., Siegel, A., and Troiano, R. Single unit analysis of hippocampal projections to the septum in the cat. Experimental Neurology, 1973, 41, 569-583.

Eichenbaum, H., Potter, H., Papsdorf, J., Butter, C.M. Effects of frontal cortex lesions on differentiation and extinction of the classically conditioned nictitating membrane response in rabbits. Journal of Comparative and Physiological Psychology, $1974,80, \frac{80}{179-186 .}$

Fried, P.A. Septum and behavior: A review. Psychological Bulletin, 1972, 78, 293-310.

Glazner, M. Stimulus satiation: An explanation of spontaneous alternation and related phenomena. Psychological Review, 1953, 60, 257-268.

Goodfellow, E.F., and Neimer, W.T. The spread of afterdischarge from stimulation of the rhinencephalon in cat. Electroencephalography and Clinical Neurophysiology, $1961,21,34-53$.

Gormezano, I. Classical Conditioning. In: J.B. Sidowski (Ed.), Experimental Methods and Instrumentation in Psychology, New York: Mc-Graw-Hill, 1966.

Gormezano, I., and Moore, J.W. Classical Conditioning. In: M.H. Marx (Ed.), Learning: Processes. London: MacMillan, 1969.

Gotsick, J.E. Factors affecting spontaneous activity in rats with limbic lesions. Physiology and Behavior, $1969, \underline{4}, 587-593$.

Gray, T., and Appignanesi, A.A. Compound conditioning: Elimination of the blocking effect. Learning and Motivation, 1973, 4, 374-380.

Greene, E., and Stauff, C. Behavioral role of hippocampal connections. Experimental Neurology, 1974, 45, 141-160.

Green, R.H., Beatty, W.W., and Schwartzbaum, J.S. Comparative effects of septo-hippocampal and caudate lesions on active avoidance behavior in rats. Journal of Comparative and Physiological Psychology, 1967, 64, $444-452$. 
Gross, C.G., Chorover, S.C., and Cohen, S.M. Caudate, cortical, hippocampal and dorsal thalamic lesions in rats: Alternations and Hebb-Williams maze performance. Neuropsycholoqia, $1965, \underline{3}, 53-68$.

Guillery, R.W. Degeneration of the postcommissural fornix and the mammillary peduncle in the rat. Journal of Anatomy (London), 1956, 90, 350-370.

Hamilton, G., and Isaacson, R.L. Changes in avoidance behavior following epileptogenic lesions of the mesencephelon. Physiology and Behavior, 1970, $5,1165-1167$.

Hearst, $E$. Some persistent problems in the analysis of conditioned inhibition. In: R.A. Boakes and M.S. Halliday (Eds.), Inhibition and Learning, New York: Academic Press, 1972 .

Hendrickson, C., Kimble, R.J., and Kimble, D.P. Hippocampal lesions and the orienting response. Journal of Comparative and Physiological Psychology, $1969,67, \frac{67}{220-227 .}$

Hirsch, R., and Segal, M. Complete transection of the fornix and reversal of position habit in the rat. physiology and Behavior, 1972, 8, 1051-1054.

Hjorth-Simonsen, A. Hippocampal efferents to the ipsilateral entorhinal area: An experimental study in the rat. Journal of Comparative Neurology, 1971, 142, 417-438.

Hjorth-Simonsen, $A_{\text {. , }}$ and Jeune, B. Origin and termination of the hippocampal perforant path in the rat studied by silver impregnation. Journal of Comparative Neurology, $1972,144,215-231$.

Hostetter, G., and Thomas, G.J. Evaluation of enhanced thigmotaxix as a condition of impaired maze learning by rats with hippocampal lesions. Journal of Comparative and Physiological Psychology, $1967,63,105-110$.

Hughes, K.R. Dorsal and ventral hippocampal lesions and maze learning and influence of postoperative environments. Canadian Journal of Psycholoqy, 1965, 19, 325-332. Hul1, C.L. Principles of Behavior. New York: Appleton- 
Ireland, L.C., and Isaacson, R.L. Reactivity in the hippocampectomized gerbil. Psychonomic Science, 1968, 12, 163-164.

Isaacson, R.L. Neural systems of the limbic brain and behavioral inhibition. In: R.A. Boakes \& M.S. Halliday (Eds.), Inhibition and Learning. New York: Academic Press, 1972 .

Isaacson, R.L. The Limbic System. New York: Plenum Press, 1974 .

Isaacson, R.L., Douglas, R.J., and Moore, R.Y. The effects of radical hippocampal ablation on acquisition of avoidance response. Journal of Comparative and Physiological Psychology, $19 \overline{61,54}, \frac{525}{-628 .}$

Isaacson, R.L., and Kimble, D.P. Lesions of the limbic system: Their effects upon hypothesis and frustration. Behavioral Biology, 1972, 7, 767-793.

Iziquierdo, I. The hippocampus and learning. Progress in Neurobiology, $1975, \underline{5}, 39-75$.

Jackson, W.J., and Strong, P.N. Differential effects of hippocampal lesions upon sequential tasks and maze learning in rats. Journal of Comparative and Physiological Psychology, $19 \overline{69,68}, 442-450$.

Jarrard, L.E. The hippocampus and motivation. Psychological Bulletin, 1973, 79, 1-12.

Jarrard, L.E., and Bunnell, B.N. Open-field behavior of hippocampal lesioned rats and hamsters. Journal of Comparative and Physiological Psychology, 1969, 66, $500-502$.

Jarrard, L.E., and Korn, J.H. Effects of hippocampal lesions on heart rate during habituation and passive avoidance. Communications in Behavioral Biology, 1969, 3, 141-150.

Jarrard, L.E., and Lewis, R.C. Effects of hippocampal ablation and intertrial interval on acquisition and extinction in a complex maze. American Journal of Psychology, 1967, 80, 66-72.

Kaada, B.R., Rasmussen, E.W., and Kviem, O. Effects of hippocampal lesions on maze learning and retention in rats. Experimental Neurology, 1961, 3, 333-355. 
Kamback, M. Effects of hippocampal lesions and food deprivation on response for stimulus change. Journal of $\frac{\text { Comparative and Physiological Psychology, 1967, }}{231-235}$.

Kamin, L.J. "Attention-like" processes in classical conditioning. In: M.R. Jones (Ed.), Miami Symposium on the Prediction of Behavior, Miami, University of Miami Press,

Kamin, L.J. Predictibility, surprise, attention, and conditioning. In: B. Campbell and R. Church (Eds.), Punishment and Aversive Behavior, New York: Appleton-Century-

Kaplan, J. Approach and inhibitory reactions in rats after bilateral hippocampal damage. Journal of Comparative and Physiological Psychology, 1968, 65, $\frac{6}{274-281 .}$

Karmos, G., and Grastyan, E. Influence of hippocampal lesions on simple and delayed conditioned reflexes. Acta Physiologica Academy Science Hungary, 1962, 21, 215-224.

Kimble, D.P. The effects of bilateral hippocampal lesions in rats. Journal of Comparative and Physioloqical Psychology, $1963, \underline{56}, 273-283$.

Kimble, D.P. The behavioral effects of hippocampal lesions in rats. Paper presented at the 75th Annual Meeting of the American Psychological Association, Washington, D.C., September, 1967.

Kimble, D.P. Hippocampus and internal inhibition. Psychological Bulletin, 1968, 70, 285-295.

Kimble, D.P., and Kimble, R.J. Hippocampectomy and response perseveration in the rat. Journal of Comparative and Physiological Psychology, $1 \overline{965}, \underline{3}, \overline{474}-476$.

Kirkby, R.J., Stein, D.G., and Kimble, D.P. Effects of hippocampal lesions and duration of sensory input on spontaneous alternation. Journal of Comparative and Physiological Psychology, 1967, 64, 342-345.

Konorski, J. The role of prefrontal control in the programming of motor behavior. In: Efferent organization and the Integration of Behavior, Jack D. Maser (Ed.), New York: Academic Press, 1973. 
Leaton, R.N. Patterns of behavior of hippocampal lesioned rats in an exploratory motivated situation. Psychological Reports, 1967, 21, 153-159.

Leonard, C.M. The prefrontal cortex of the rat. Cortical projection of the mediodorsal nucleus. II. Efferent connections. Brain Research, 1969, 12, 321-343.

Lewis, P.R. and Schute, C.C.D. The cholinergic limbic system: Projections to the hippocampal formation, medial fornix, ruclei of the ascending cholinergic reticular system, and the subfornical organ and supraoptic crest. Brain, $1967, \underline{40}$, 521-540.

Liss, P. Avoidance and freezing behavior following damage to the hippocampus and fornix. Journal of Comparative and Physiological Psychology, 1968, 66, $193-197$.

Lubow, R.E. Latent inhibition. Psychological Bulletin, $1973, \underline{79}, 398-407$.

Mackintosh, N.J. Stimulus selection: Learning to ignore stimuli that predict no change in reinforcement. In: R.A. Hinde and J. Stevenson-Hinde (Eds.) Constraints on Learning. New York: Academic Press, 1973.

Mackintosh, N.J. and Turner, C. Blocking as a function of novelty of CS and predictability of UCS. Quarterly Journal of Experimental Psychology, 1971, $\underline{23}, 359-366$.

Marchant, H.G., Mis, F.W., and Moore, J.W. Conditioned inhibition of the rabbits nictitating membrane response. Journal of Experimental Psychology, 1972, 95, 408-411.

Marchant, H.G., and Moore, J.W. Blocking of the rabbits conditioned nictitating membrane response in Kamin's two-stage paradigm. Journal of Experimental psychology, $1973,101,155-158$.

Marchant, H.G., and Moore, J.W. Below-zero conditioned inhibition of the rabbit's nictitating membrane response. Journal of Experimental Psychology, 1974, 102, 350-352.

McCleary, R.A. Response-modulating functions of the limbic system: Initiation and suppression. In: E. Stellar and J.M. Sprague (Eds.), progress in physiological p'sychology, Vol. 1, New York: Academic Press, 1966. 
McNew, J.J., and Thompson, R. Role of the limbic system in active and passive avoidance conditioning in the $r$ at. Journal of Comparative and Physiological Psychology, $1966,61,173-180$.

Micco, D.J. and Schwartz, M. Effects of hippocampal lesions upon the development of Pavlovian internal inhibition.

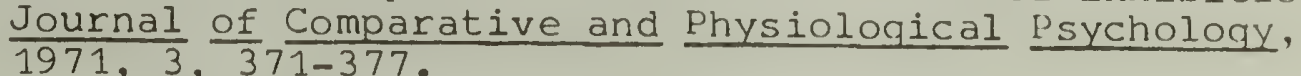

Mis, F.W. Midbrain and brain stem mechanisms of conditioned inhibition of the rabbit's nictitating membrane response. Unpublished Doctoral Dissertation, University of Massachusetts, 1975.

Moore, J.W. Stimulus control: Studies of auditory generalization in rabbits. In: A.H. Black and W.F. Prokasy (Eds.) Classical Conditioning II: Current Theory and Research. New York: Appleton-Century-Crofts, 1972.

Moore, J.W. Contextual constraints on Pavlovian inhibitory control. Paper presented at the Annual Meeting of the American Psychological Association, New Orleans, 1974.

Moore, J.W., Marchant, H.G., Norman, J.B. and Kwaterski, S.E. Electrical brain stimulation as a Pavlovian conditioned inhibitor. Physiology and Behavior, 1973, 10, 581-587.

Morest, D.K. Connections of the dorsal tegmental nuclei in rat and rabbit. Journal of Anatomy, 1971, 93, 229-213.

Myers, J.L. Fundamentals of Experimental Design. Boston: Allyn and Bacon, 1972 .

Nadel, L. Dorsal and ventral hippocampal lesions and behavior. Physiology and Behavior, 1968, 3, 891-900.

Nadel, L., and O'Keefe, J. The hippocampus in pieces and patches: An essay on models of explanation in physiological psychology. In: R. Bellaris, and E.G. Gray (Eds.), Essays on the Nervous System. London: Oxford University Press, 1974 .

Nauta, W.J.H. An experimental study of the fornix in the rat. Journal of Comparative Neurology, $1956,104,247-$ 272 .

Nauta, W.J.H. Hippocampal projections and related neural pathways to the midbrain in the cat. Brain, 1958, 81, $319-340$. 
Nauta, W.J.H. Neural associations of the frontal cortex. Acta Neurobiologica Experimentalis, $1972,30,33-42$.

Nauta, W.J.H. and Kypers, H.G.J.M. Some ascending pathways in the brainstem reticular formation. In: H.H. Jasper et al. (Eds.) Reticular Formation of the Brain. Boston: Little, Brown, and Compnay, 1958.

Niki, H. The effects of hippocampal ablation on inhibitory control of operant behavior in the rat. Japanese

Psycholorical Research, 1965, 7, 126-137.

Niki, H. Response perseveration following hippocampal ablation in the rat. Japanese Psychological Research, 1966 , 8, $1-9$.

Nonneman, A.J., Voight, J., and Kolb, B.E. Comparisons of behavioral effects of hippocampal and prefrontal cortex lesions in the rat. Journal of Comparative and Physiological Psychology, $19 \overline{74,87}, \frac{1}{249} 9.260$.

Norman, R.J., Villablanca, J.R., Brown, K.A., Schwafel, J.A. and Buchwald, J.S. Classical eyeblink conditioning in the bilaterally hemispherectomized cat. Experimental Neurology, $1974,44,363-380$.

Oakley, D.A. and Russell, I.S. Neocortical lesions and Pavlovian conditioning. Physiology and Behavior, 1972, $\underline{9}, 915-926$.

Oakley, D.A. and Russell, I.S. Differential and reversal conditioning in partially neocorticate rabbits. Physiology and Behavior, 1974, 13, 211-230.

O'Keefe, L., and Nadel, L. The Hippocampus: A Cognitive Map. London: Oxford University press, 1974.

Oliverio. D. Effects of scopolamine on avoidance conditioning and habituation in mice. Psychopharmacologia, $1968,12,214-226$.

Olton, D.S. Discrimination reversal performance after hippocampal lesions: An enduring failure of reinforcement and nonreinforcement to direct behavior. Physiology and Behavior, $1972, \underline{9}, 353-356$.

Olton, D.S. and Isaacson, R.I. Hippocampal lesions and active avoidance. Physiology and Behavior, 1968, 3 , 719-724. 
Orbach, J., Milner, B., and Rasmussen, T. Learning and retention in monkeys after amygdala-hippocampal resection. Archives of Neurology, 1960, 3, 230-251.

Papez, J.W. A proposed mechanism of emotion. Archives of Neurology and Psychiatry, $1937, \underline{38}, 725-7 \overline{34}$. Pavlov, I.P. Conditioned Reflexes. Oxford University Press,
London, 1927 .

Penfield, W., and Milner, B. Memory deficits produced by bilateral lesions in the hippocampal zone. Archives of Neurology and Psychiatry, 1958, 79, 475-4 $\overline{97}$.

Rabe, A., and Haddad, R.K. Acquisition of two-way shuttle box avoidance after selective hippocampal lesions. Physiology and Behavior, 1968, 4, 319-323.

Rabe, A., and Haddad, R.K. Effect of selective hippocampal lesions in the rat on acquisition, performance, and extinction of bar pressing on a fixed ratio schedule. Experimental Brain Research, 1968, 2, 259-266.

Racine, R.J. and Kimble, D.P. Hippocampal lesions and delayed alternation in the rat. Psychonomic Science, $1965, \underline{3}, 285-286$.

Raisman, G., Cowan, W.M. and Powell, T.P.S. An experimental analysis of the afferent projections of the hippocampus. Brain, 1965, 88, 963-996.

Raphelson, A.C., Isaacson, R.L. and Douglas, R.J. The effect of distracting stimuli on runway performance of limbic damaged rats. Psychonomic Science, 1965, 3, 483-484.

Razran, G. Empirical codification and specific theoretical implications of compound stimulus conditioning: Perception. In: W. prokasy (Ed.) Classical Conditioning. New York: Appleton-Century-Crofts, 1965.

Reberg, D. Compound tests for extinction in early acquisition and after prolonged extinction of conditioned suppression. Learning and Motivation, 1972, $\underline{3}, 246-258$.

Reiss, S., and Wagner, A.R. CS habituation produces a "latent inhibition" effect but no active conditioned inhibition. Learning and Motivation, 1972, 3 , 237- 245.

Rescorla, R.A. Pavlovian conditioned inhibition. Psychological Bulletin, 1969, 72, 77-94. 
Rescorla, R.A. Summation and retardation tests of latent inhibition. Journal of Comparative and Physiological

Rescorla, R.A. Variation in the effectiveness of reinforcement and nonreinforcement following prior inhibitory conditioning. Learning and Motivation, 1971, 2, 113-123.

Rescorla, K.A., and Wagner, A.R. A theory of Pavlovian conditioning: Variations in the effectiveness of reinforcement and nonreinforcement. In: A.H. Black and W.F. Prokasy (Eds.), Classical Conditioning II: Current $\frac{\text { Research }}{1972 .}$ and Theory, New York: Appleton-Century-Crofts,

Samuels, S. Hippocampal lesions in the rat: Effects on spatial and visual habits. Physiology and Behavior, $1971, \underline{8}, 1093-1098$.

Sandwald, J.C., Porzio, N.R., Deane, D.E., and Donavick, P.J. The effects of septal and dorsal hippocampal lesions on the cardiac component of the orienting response. Physiology and Behavior, 1970, 포 883-888.

Schlosberg, A.J., Johnson, C.N., and Lash, L. Response to shock by hippocampectomized rats. Paper presented at the Meeting of the Eastern Psychological Association, Philadelphia, April, 1969.

Schmaltz, L.W., and Isaacson, R.L. The effects of preliminary training on DRL-20 performance in the hippocampectomized rat. Physiology and Behavior, 1966, 1, 175-182.

Schmaltz, L.W., and Theios, J. Acquisition and extinction of a classically conditioned response in hippocampectomized rabbits, (Oryctolaqus cuniculus). Journal of Comparative and Physiological psychology, 1972, 79, 328-333.

Schute, C.C.D., and Lewis, P.R. The ascending cholinergic reticular system: Neacortical, olfactory, and subcortical projections. Brain, 1967, 40, 497-519.

Scoville, W.B., and Correll, R.E. Memory and the temporal lobe. Acta Neurochirurqica, 1973, 28, 251-258.

Scoville, W.B. and Milner, B. Loss of recent memory after bilateral hippocampal lesions. Journal of Neurology, Neurosurgery, and pychiatry, $1957, \underline{20}, 11-21$. 
Sengstake, C.B. Habituation and activity patterns of rats with large hippocampal lesions under various drive conditions. Journal of Comparative and Physiological Psychology, $1 \overline{968, \underline{65}}, \frac{15}{50-506 .}$

Siegel, A., and Tassoni, J.P. Differential efferent projections from the ventral and dorsal hippocampus of the cat. Brain, Behavior, and Evolution, 1971, 4, 185-

Siegel, S. Latent inhibition and eyelid conditioning. In: A.H. Black and W.F. Prokasy, (Eds.), Classical Conditioning II: Current Research and Theory, New York: Appleton-Century-Crofts, 1972.

Solomon, P.R., Brennan, G., and Moore, J.W. Latent inhibition of the rabbits nictitating membrane response as a function of CS intensity. Bulletin of the Psychonomic Society, 1974a, 4, 445-449.

Solomon, P.R., Lohr, A.C., and Moore, J.W. Latent inhibition of the rabbits nictitating membrane response: Summation tests for active inhibition as a function of number of CS preexposures. Bulletin of the Psychonomic Society, $1974 \mathrm{~b}, \underline{4}, 557-559$.

Solomon, P.R., and Moore, J.W. Latent inhibition and stimulus generalization of the classically conditioned nictitating membrane response in rabbits (Oryctolaqus cuniculus) following dorsal hippocampal ablation. Journal of Comparative and Physiological Psychology, in press.

Stevens, R. Effects of duration of sensory input and intertrial interval on spontaneous alternation in rats with hippocampal lesions. Physiological Psychology, 1973, $1,41-44$.

Stevens, R., and Coway, A. Effects of dorsal and ventral hippocampal lesions on spontaneous alternation, learned alternation and probability learning in rats. Brain Research, 1973, 52, 203-224.

Suits, E., and Isaacson, R.L. The effects of scopolamine hydrobromide on one-way and two-way active avoidance learning in rats. International Review of Neuropharmacology, $1968, \underline{7}, 44 \overline{1-446 .}$

Sutherland, N.S., and Mackintosh, N.J. Mechanisms of Animal Discrimination Learning. New York: Academic Press, 1971. 
Swanson, A.M. and Isaacson, R.L. Hippocampal ablation and performance during withdrawal of reinforcement. Journal.

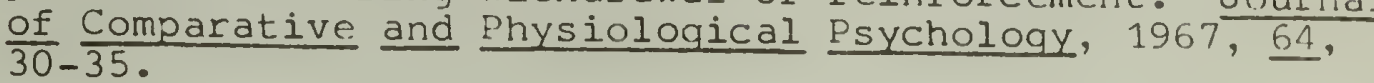

Tauklis, H.K. and Revusky, S.H. Odor as a conditioned inhibitor: Applicability of the Rescorla-wagner model to feeding behavior. Learning and Motivation, 1975, 6 , 11-27.

Thomas, G.J. Maze retention by rats with hippocampal lesions and fornicotomies. Journal of Comparative and Physiological Psychology, 1971, 75, 45-49.

Thompson, R., and Langer, S.K. Deficits in position reversal learning following lesions of the limbic system. Journal of Comparative and Physiological Psychology, 1963, 56, $987-995$.

Valenstein, E.S., and Nauta, W.J.H. A comparison of the fornix system in the rat, guinea pig, cat, and monkey. Journal of Comparative Neurology, $1959,113,337-363$.

Vanderwolf, C.H. Limbic-diencehpalic mechanisms of voluntary movement. Psychological Review, 1971, 78, 83-113.

Van Hoesen, G.W., Macdougal, J.W. and Mitchell, J.C. Anatomical specificity of the septal projections in active and passive avoidance in rats. Journal of Comparative and Physiological Psychology, 1969, 68, 80-89.

Van Hoesin, G.W., Pandya, D.N., and Butters, N. Cortical efferents to the entorhinal cortex of the Rhesus monkey. Science, 1972, 175, 1471-1473.

Van Hoesen, G.W., Wilson, L.M., Macdougal, J.W., and Mitchell, J.C. Selective hippocampal complex deafferentiation and deeferentation and avoidance behavior in rats. Physiology and Behavior, 1972, 으, 873-879.

Warburton, D.M. The cholinergic control of internal inhibition. In: R.A. Boakes, and M.S. Halliday (Eds.), Inhibition and Learning, New York: Academic Press, 1972.

Warburton, D.M., and Russell, R.W. Some behavioral effects of cholinergic stimulation of the hippocampus. Lifo Sciences, 1969, 8, 617-620. 
Weiss, K.R., and Brown, B.L. Latent inhibition: A review and new hypothesis. Acta Neurobiologica Experimentalis,

White, S.R. Atropine, scopolamine, and hippocampal lesions effects on alternation performance of rats. Pharmacology, Biochemistry, and Behavior, 1974, 2 ,

Whitlock, D.G., and Nauta, W.J.H. Subcortical projections from the temporal neocortex in Macca mulatta. Journal of Comparative Neurology, $1956, \underline{106}, \frac{183-212}{183}$

Zielinski, K., and Czarkowski, J. Go-no go avoidance reflex differentiation and its retention after prefrontal lesions in cats. Acta Neurobiologica Experimentalis, $1973, \underline{33}, 467-490$.

Zielinski, K., and Czarkowska, J. Quality of stimuli and prefrontal lesions effects on reversal learning in gono go avoidance reflex differentiation in cats. Acta Neurobiologica Experimentalis, 1974, 34, 43-68.

Zimmer-Hart, C., and Rescorla, R.A. Extinction of Pavlovian conditioned inhibition. Journal of Comparative and Physiological Psychology, 1974, 86, 837-845. 
Appendix A

Conditioned Responding for each animal during the three phases of Experiment 1 
Table 1

Conditioned Responding to Tone During Stage 1

\begin{tabular}{|c|c|c|c|c|c|c|}
\hline GROUP & SUBJECT & DAY 1 & DAY 2 & DAY 3 & DAY 4 & TOTAL \\
\hline $\mathrm{H}-\mathrm{BLO}$ & $\begin{array}{l}\text { H6 } \\
\text { H7 } \\
H 10 \\
\text { H11 } \\
\text { H13 } \\
\frac{x}{x}\end{array}$ & $\begin{array}{l}67 \\
85 \\
71 \\
61 \\
73 \\
71.4\end{array}$ & $\begin{array}{r}100 \\
98 \\
95 \\
99 \\
95 \\
97.4\end{array}$ & $\begin{array}{r}99 \\
100 \\
100 \\
99 \\
98 \\
99.2\end{array}$ & $\begin{array}{l}-- \\
-- \\
-- \\
-- \\
-- \\
--\end{array}$ & $\begin{array}{l}266 \\
283 \\
266 \\
259 \\
266\end{array}$ \\
\hline $\mathrm{C}-\mathrm{BLO}$ & $\begin{array}{l}\text { C4 } \\
C 5 \\
C 7 \\
C 9 \\
C 15 \\
\frac{1}{x}\end{array}$ & $\begin{array}{c}0 \\
77 \\
75 \\
8 \\
61 \\
44.2\end{array}$ & $\begin{array}{l}12 \\
99 \\
95 \\
94 \\
92 \\
78.4\end{array}$ & $\begin{array}{r}82 \\
99 \\
100 \\
99 \\
95 \\
95.0\end{array}$ & $\begin{array}{l}96 \\
-- \\
-- \\
-- \\
-- \\
96\end{array}$ & $\begin{array}{l}190 \\
275 \\
270 \\
201 \\
248\end{array}$ \\
\hline $\mathrm{N}-\mathrm{BLO}$ & $\begin{array}{l}\text { N1 } \\
\text { N2 } \\
\text { N3 } \\
\text { N4 } \\
\text { N9 } \\
\bar{x}\end{array}$ & $\begin{array}{l}67 \\
40 \\
73 \\
2 \\
90 \\
54.4\end{array}$ & $\begin{array}{l}100 \\
100 \\
100 \\
98 \\
83 \\
96.2\end{array}$ & $\begin{array}{r}99 \\
98 \\
100 \\
100 \\
100 \\
99.4\end{array}$ & $\begin{array}{l}-- \\
-- \\
-- \\
-- \\
96 \\
96\end{array}$ & $\begin{array}{l}266 \\
238 \\
273 \\
200 \\
369\end{array}$ \\
\hline
\end{tabular}


Table 2

Conditioned Responding to Light + Tone During Stage 2 GROUP SUBJECT DAY 1 DAY 2 DAY 3 DAY DAY 5 TOTAL $\mathrm{H}-\mathrm{BLO}$

H6

$\mathrm{H} 7$

H 10

H 11

H $\frac{13}{x}$

95

99

100

100

92
97.2

100

100

100

100

100

495

100

100

100

100

100

91

100

100

$93 \quad 82$

97.6

94.6

98

98

$99.6 \quad 99.6$

499

500

486

463

C-BLO

$\begin{array}{rr}\text { C4 } & 99 \\ \text { C5 } & 100 \\ \text { C7 } & 100 \\ \text { C9 } & 99\end{array}$

C 15

99

97

99.0

100

96

100

100

95

98.2

99

100

99

98

99

99.0
95

99

100

100

100

98.8
$\mathrm{N}-\mathrm{BLO}$

$\mathrm{N} 1$
$\mathrm{~N} 2$
$\mathrm{~N} 3$
$\mathrm{~N} 9$

N1

N2

N3

N4

$\mathrm{N} \frac{9}{\mathrm{x}}$

98

98

97

99

100

98.4
99

100

100

100

93

98.4

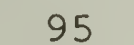

98

100

100

100

98.6

\section{0}

100

100

100

100

100
98

99

100

100

98

99.0
491

494

499

477

489

\begin{tabular}{lllrrrrr}
\hline \multirow{3}{*}{ H-SIT } & H4 & 26 & 63 & 99 & 98 & 99 & 385 \\
& H8 & 47 & 100 & 100 & 100 & 100 & 447 \\
& H14 & 31 & 99 & 98 & 94 & 96 & 418 \\
& H15 & 88 & 98 & 99 & 99 & 99 & 402 \\
& H16 & 87 & 98 & 100 & 100 & 99 & 484 \\
& $\tilde{x}$ & 55.8 & 91.6 & 99.2 & 98.2 & 98.6 & \\
\hline \multirow{2}{*}{ C-SIT } & C3 & 84 & 100 & 80 & 97 & 97 & 458 \\
& C6 & 87 & 98 & 100 & 100 & 99 & 484 \\
& C11 & 73 & 100 & 100 & 100 & 100 & 473 \\
& C12 & 51 & 91 & 98 & 98 & 96 & 434 \\
& C13 & 96 & 87 & 99 & 100 & 98 & 480 \\
& $\bar{x}$ & 78.2 & 95.2 & 95.4 & 95.6 & 98.0 & \\
\hline
\end{tabular}


Table 2 (continued)

\begin{tabular}{|c|c|c|c|c|c|c|c|}
\hline GROUP & SUBJECT & DAY 1 & DAY 2 & DAY 3 & DAY 4 & DAY 5 & TOTAL, \\
\hline$N-S I T$ & N5 & 40 & 95 & 100 & 99 & 100 & 434 \\
\hline & N6 & 78 & 100 & 99 & 100 & 97 & 474 \\
\hline & N7 & 0 & 62 & 100 & 100 & 100 & 362 \\
\hline & N8 & 11 & 100 & 100 & 100 & 100 & 411 \\
\hline & $\mathrm{N}_{\frac{1}{x}} 0$ & $\begin{array}{l}59 \\
37.6\end{array}$ & $\begin{array}{l}100 \\
91.4\end{array}$ & $\begin{array}{l}94 \\
98.6\end{array}$ & $\begin{array}{l}93 \\
98.4\end{array}$ & $\begin{array}{l}98 \\
99.0\end{array}$ & 444 \\
\hline
\end{tabular}


Table 3

Conditioned Responding to Light and Tone During The Test Phase

\begin{tabular}{|c|c|c|c|c|c|c|}
\hline GROUP & SUBJECT & $\begin{array}{c}\text { DAY } \\
\text { LIGHT }\end{array}$ & $\frac{1}{\text { TONE }}$ & $\begin{array}{c}\text { DAY } \\
\text { LIGHT } \\
\end{array}$ & $\frac{2}{\text { TONE }}$ & $\frac{\mathrm{RATIO}}{\mathrm{L} / \mathrm{L}+\mathrm{T}}$ \\
\hline $\mathrm{H}-\mathrm{BLO}$ & $\begin{array}{l}\text { H6 } \\
\text { H7 } \\
\text { H10 } \\
\text { H11 } \\
\text { H1 } \frac{1}{x}\end{array}$ & $\begin{array}{l}42 \\
41 \\
50 \\
28 \\
25\end{array}$ & $\begin{array}{l}44 \\
42 \\
47 \\
30 \\
36\end{array}$ & $\begin{array}{r}13 \\
49 \\
40 \\
12 \\
2\end{array}$ & $\begin{array}{r}33 \\
50 \\
31 \\
26 \\
9\end{array}$ & $\begin{array}{r}.42 \\
.49 \\
.54 \\
.42 \\
.38 \\
.45\end{array}$ \\
\hline$C-B L O$ & $\begin{array}{l}\text { C4 } \\
\text { C5 } \\
\text { C7 } \\
\text { C9 } \\
\text { C } 15 \\
\frac{x}{5}\end{array}$ & $\begin{array}{r}15 \\
9 \\
3 \\
20 \\
19\end{array}$ & $\begin{array}{l}41 \\
24 \\
45 \\
50 \\
47\end{array}$ & $\begin{array}{r}11 \\
3 \\
4 \\
21 \\
15\end{array}$ & $\begin{array}{l}34 \\
24 \\
50 \\
50 \\
48\end{array}$ & $\begin{array}{r}.26 \\
.20 \\
.07 \\
.29 \\
.26 \\
.21\end{array}$ \\
\hline$N-B L O$ & $\begin{array}{l}\text { N1 } \\
\text { N2 } \\
\text { N3 } \\
\text { N4 } \\
\text { N9 } \\
\frac{x}{x}\end{array}$ & $\begin{array}{r}2 \\
11 \\
1 \\
2 \\
21\end{array}$ & $\begin{array}{l}48 \\
36 \\
42 \\
49 \\
48\end{array}$ & $\begin{array}{r}5 \\
13 \\
2 \\
0 \\
8\end{array}$ & $\begin{array}{l}45 \\
38 \\
30 \\
48 \\
41\end{array}$ & $\begin{array}{r}.07 \\
.24 \\
.04 \\
.02 \\
.25 \\
.12\end{array}$ \\
\hline $\mathrm{H}-\mathrm{SIT}$ & $\begin{array}{l}\text { H4 } \\
\text { H8 } \\
\text { H } 14 \\
\text { H } 15 \\
\text { H16 } \\
\frac{1}{x}\end{array}$ & $\begin{array}{r}28 \\
34 \\
33 \\
18 \\
9\end{array}$ & $\begin{array}{l}31 \\
26 \\
41 \\
22 \\
19\end{array}$ & $\begin{array}{r}28 \\
20 \\
11 \\
60 \\
0\end{array}$ & $\begin{array}{r}27 \\
35 \\
9 \\
62 \\
0\end{array}$ & $\begin{array}{r}.49 \\
.47 \\
.47 \\
.49 \\
.33 \\
.45\end{array}$ \\
\hline C-SIT & $\begin{array}{l}\text { C3 } \\
\text { C6 } \\
\text { C } 11 \\
C 12 \\
C 13 \\
C_{13}\end{array}$ & $\begin{array}{r}44 \\
46 \\
36 \\
2 \\
23\end{array}$ & $\begin{array}{r}38 \\
47 \\
47 \\
0 \\
33\end{array}$ & $\begin{array}{r}31 \\
45 \\
10 \\
5 \\
18\end{array}$ & $\begin{array}{r}28 \\
47 \\
14 \\
8 \\
32\end{array}$ & $\begin{array}{r}.54 \\
.49 \\
.43 \\
.47 \\
.39 \\
.46\end{array}$ \\
\hline
\end{tabular}


Table 3 (continued)

\begin{tabular}{|c|c|c|c|c|c|c|}
\hline GROUP & SUBJECT & DAY & 1 & DAY & 2 & RATIO \\
\hline & & LIGHT & TONE & LIGHT & TONE & $\mathrm{L} / \mathrm{L}+\mathrm{T}$ \\
\hline $\mathrm{N}-\mathrm{SIT}$ & $\begin{array}{l}\text { N5 } \\
\text { N6 } \\
\text { N7 } \\
\text { N8 } \\
\text { N10 } \\
\frac{1}{x}\end{array}$ & $\begin{array}{r}25 \\
7 \\
10 \\
15 \\
36\end{array}$ & $\begin{array}{r}20 \\
7 \\
42 \\
49 \\
41\end{array}$ & $\begin{array}{r}23 \\
12 \\
6 \\
27 \\
35\end{array}$ & $\begin{array}{l}35 \\
21 \\
17 \\
48 \\
46\end{array}$ & $\begin{array}{l}.46 \\
.40 \\
.21 \\
.30 \\
.45 \\
.36\end{array}$ \\
\hline
\end{tabular}


Appendix B

Conditioned responding for each animal during differentiation and retardation in Experiment 2 


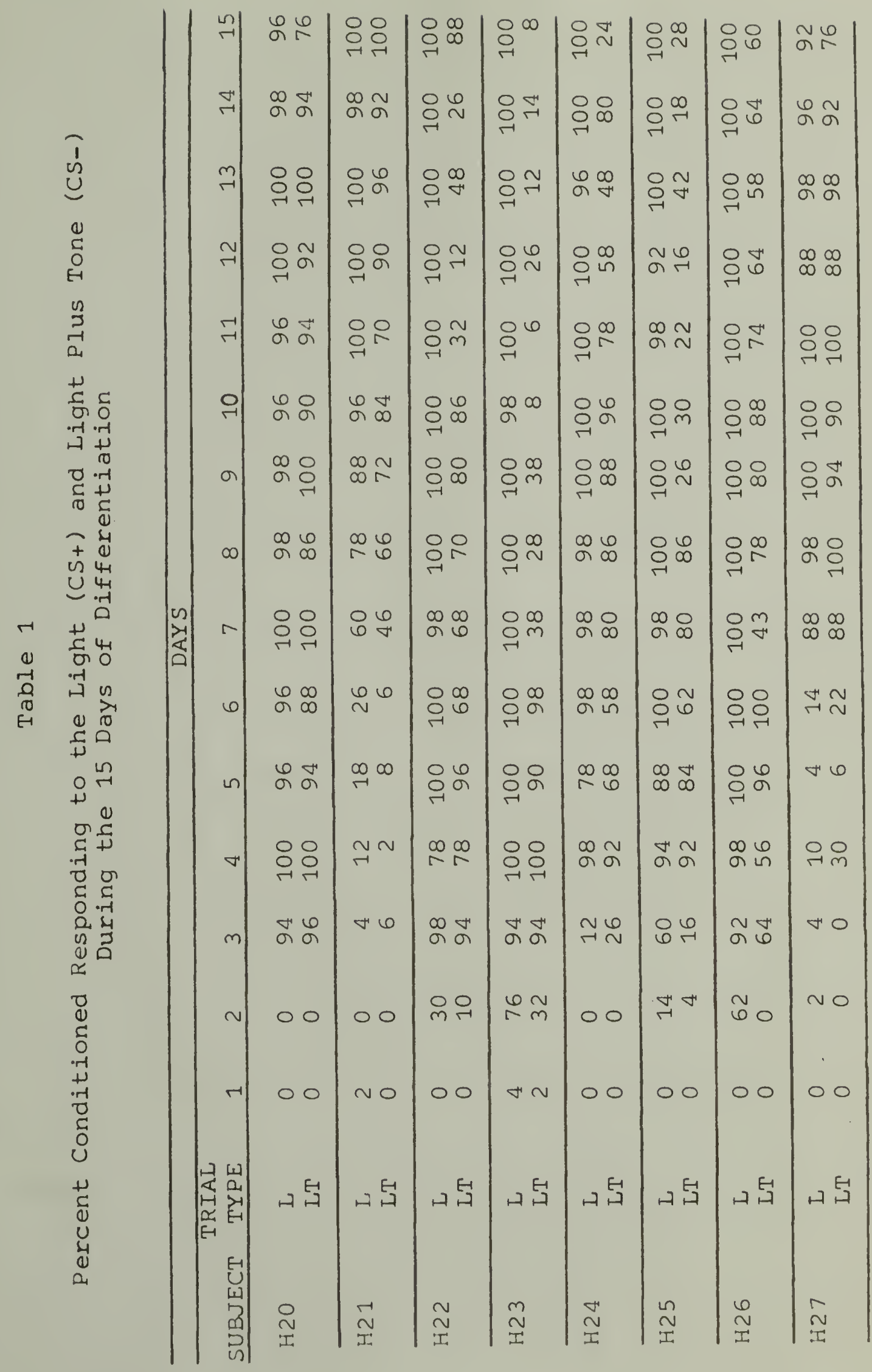




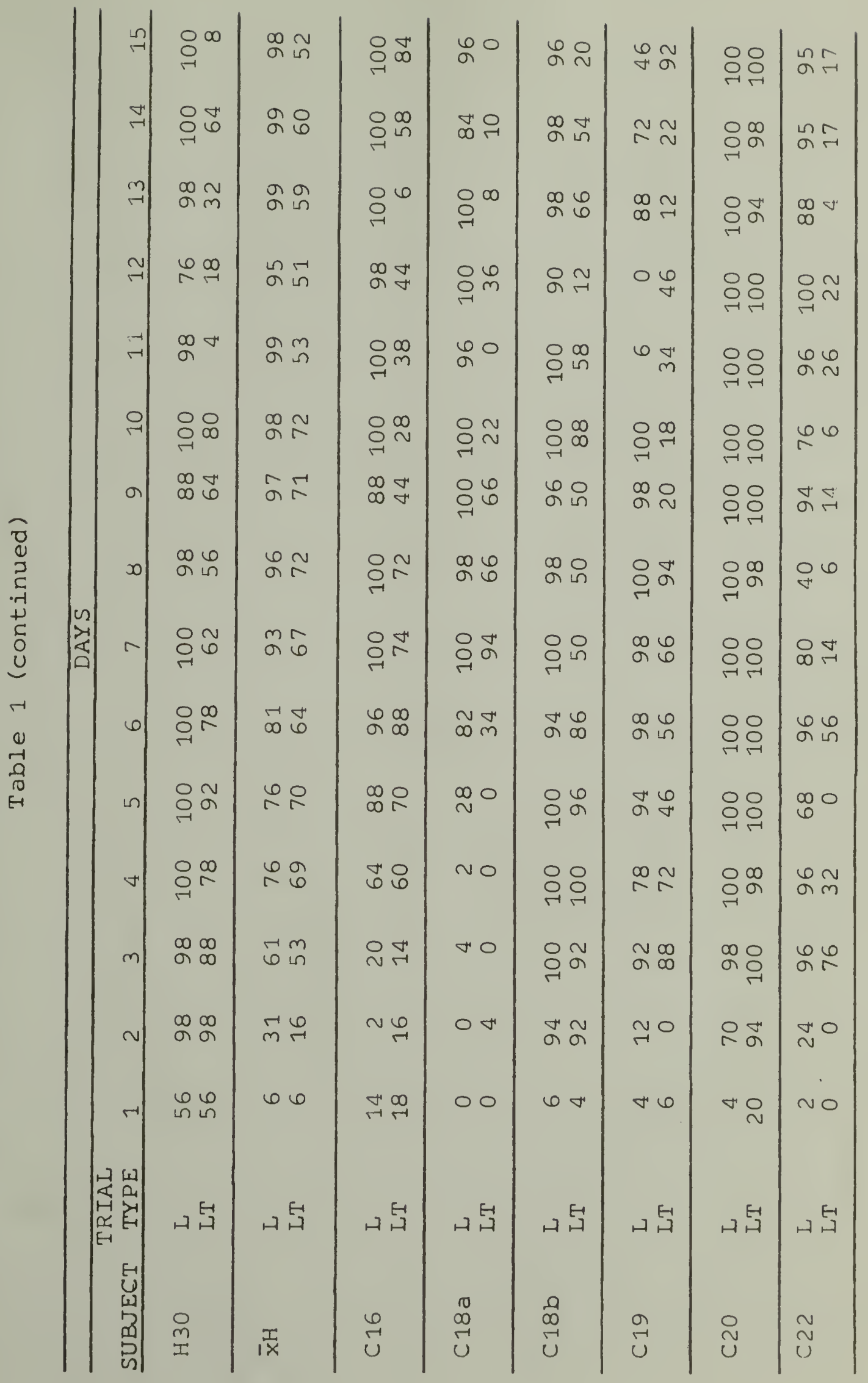




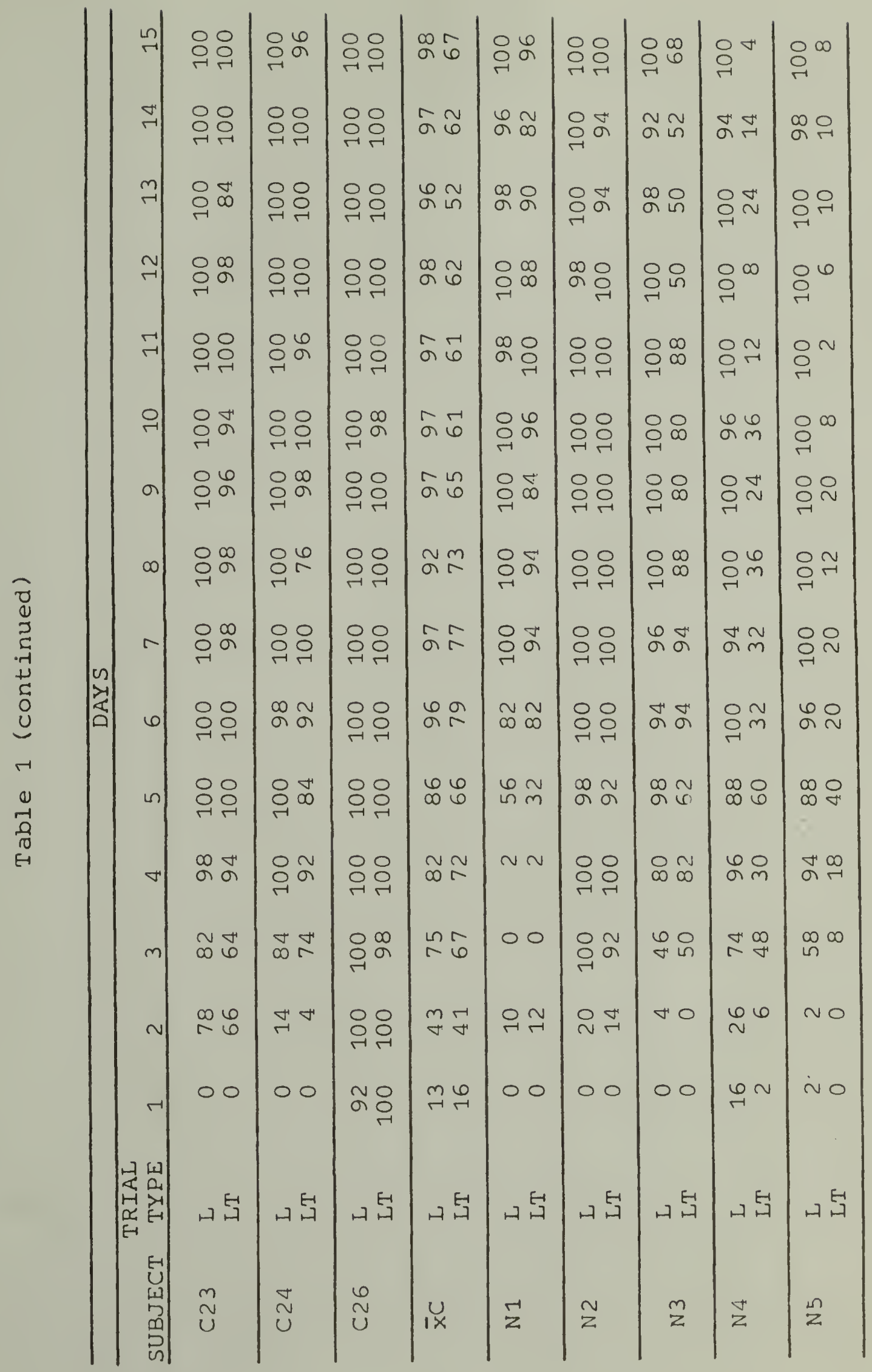




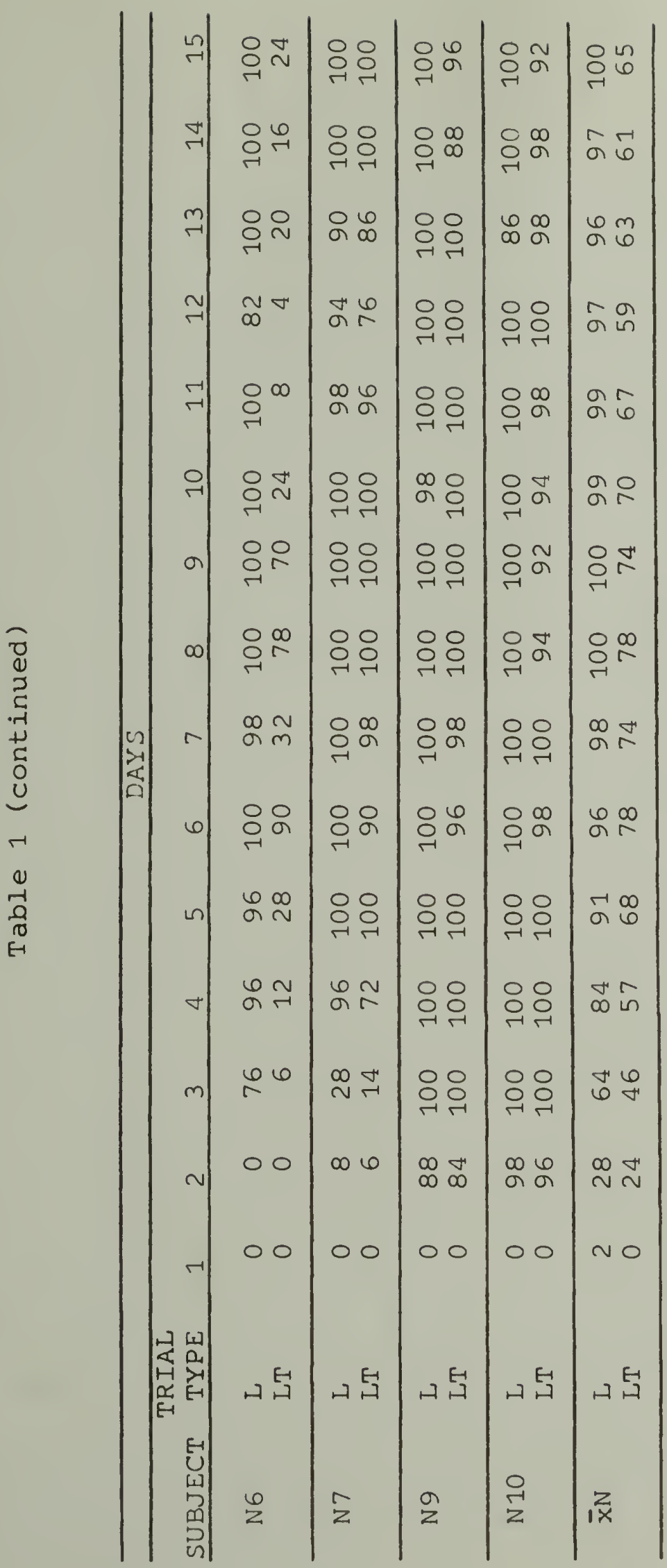




\section{Table 2}

Conditioned Responding to Tone During Retardation Testing

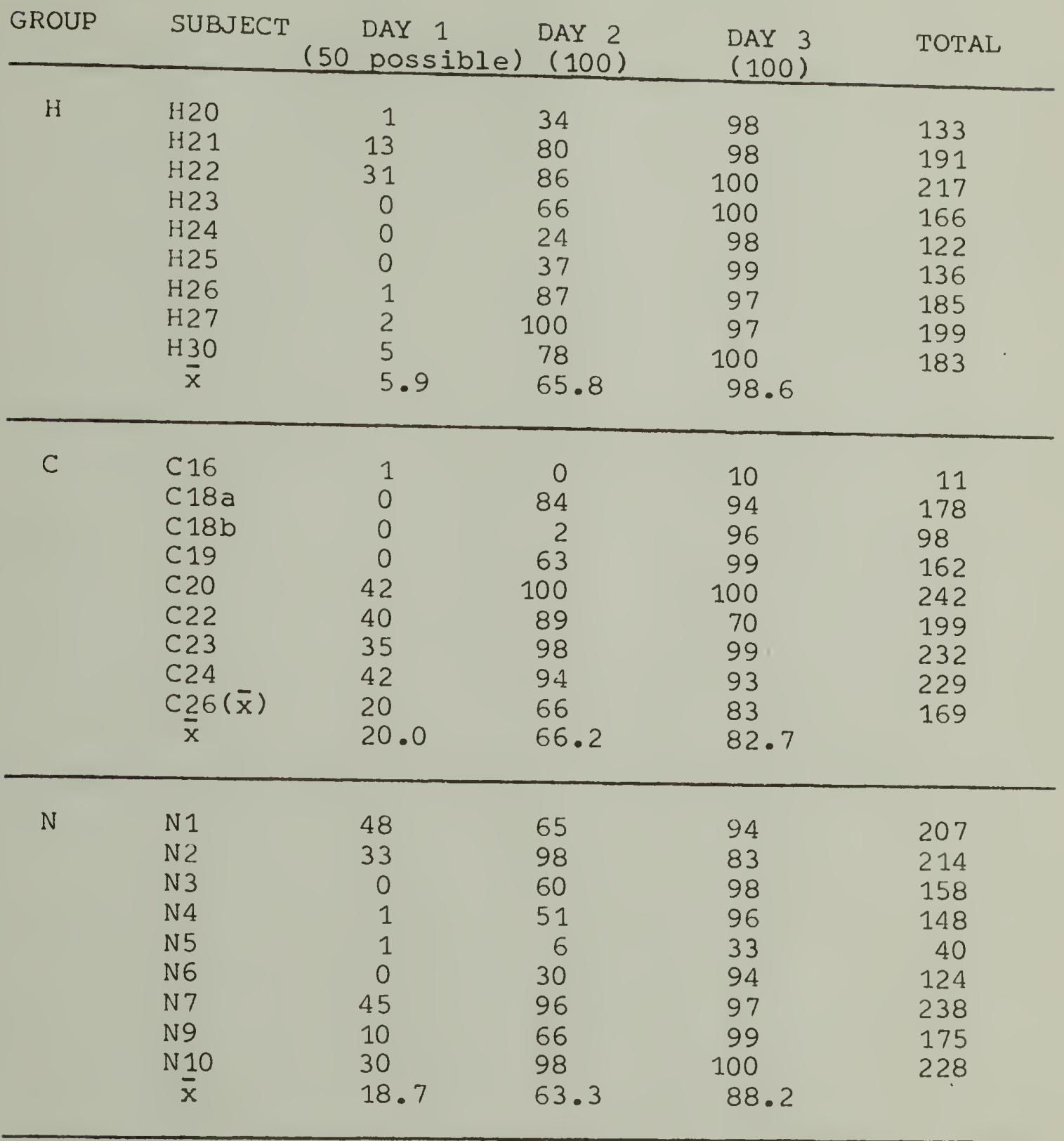


Table 3

Number of Trials to Reach Criterion

During Retardation Testing

\begin{tabular}{|c|c|c|c|c|}
\hline GROUP & SUBJECTS & 5 CONSECUTIVE CRS & 10 CONSECUTIVE & CRs \\
\hline $\mathrm{H}$ & $\begin{array}{l}\mathrm{H} 20 \\
\mathrm{H} 21 \\
\mathrm{H} 22 \\
\mathrm{H} 23 \\
\mathrm{H} 24 \\
\mathrm{H} 25 \\
\mathrm{H} 26 \\
\mathrm{H} 27 \\
\mathrm{H} 30 \\
\bar{x}\end{array}$ & $\begin{array}{r}66 \\
128 \\
25 \\
91 \\
140 \\
132 \\
85 \\
55 \\
72 \\
88.2\end{array}$ & $\begin{array}{r}94 \\
133 \\
30 \\
96 \\
163 \\
162 \\
113 \\
60 \\
77 \\
103.1\end{array}$ & \\
\hline$C$ & $\begin{array}{l}\text { C16 } \\
\text { C } 18 a \\
\text { C } 18 b \\
\text { C } 19 \\
\text { C20 } \\
\text { C22 } \\
\text { C23 } \\
\text { C24 } \\
\text { C } 26(\bar{x}) \\
\bar{x}\end{array}$ & $\begin{array}{r}170 \\
257 \\
160 \\
84 \\
13 \\
6 \\
21 \\
11 \\
90 \\
90.2\end{array}$ & $\begin{array}{r}175 \\
278 \\
165 \\
122 \\
30 \\
11 \\
26 \\
16 \\
103 \\
102.9\end{array}$ & \\
\hline $\mathrm{N}$ & $\begin{array}{l}\text { N1 } \\
\text { N2 } \\
\text { N3 } \\
\text { N4 } \\
\text { N5 } \\
\text { N6 } \\
\text { N7 } \\
\text { N9 } \\
\text { N10 } \\
\frac{1}{x}\end{array}$ & $\begin{array}{r}5 \\
25 \\
117 \\
105 \\
215 \\
127 \\
5 \\
100 \\
39 \\
82.0\end{array}$ & $\begin{array}{r}10 \\
30 \\
122 \\
110 \\
259 \\
132 \\
10 \\
127 \\
44 \\
93.8\end{array}$ & . \\
\hline
\end{tabular}


Appendix C

Results of the Statistical Analysis Performed in Experiment 1 
Table 1

ANOVA on the L/L+T Ratios Generated During the Test Phase

\begin{tabular}{lrrr} 
SV & DF & MS & \multicolumn{1}{c}{} \\
\hline Lesion Type (L) & 2 & $1,062.5$ & $14.59 * *$ \\
Sit vS Block (T) & 1 & $1,984.5$ & $27.23 * *$ \\
L X T & 2 & 496.5 & $6.82 *$ \\
S/LT & 24 & 72.8 & \\
\hline
\end{tabular}

* $p<.005$

$* * p<.001$

Table 2

ANOVA on the L/L+T Ratios Generated During The Test Phase-Simple Effects

SV

DF

MS

F

Hippocampal

vs. Normal (L)

Sit vs Block( $T$ )

$\mathrm{L} \times \mathrm{T}$

S/LT

1
1
1
12

$2,121.8$

720.0

719.2

72.8

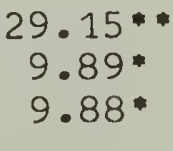

. $p<.01$

** $p<.001$

SV

DF MS

F

Hippocampal vs

\begin{tabular}{lrrr} 
Control (L) & 1 & 768.8 & $10.6 * *$ \\
Sit vs Block (T) & 1 & 605.0 & $8.31 * *$ \\
L X T & 1 & 768.8 & $10.6 * *$ \\
S/LT & 12 & 72.8 & \\
\hline
\end{tabular}

$\therefore p<.025$

** $p<.01$

SV

Cortical vs Normal(L) 1 Sit vs Block (T)

$\mathrm{L} \times \mathrm{T}$

1

$\mathrm{S} / \mathrm{LT}$

MS

F

$\begin{array}{rc}460.8 & 6.33^{*} \\ 2,976.8 & 40.89^{* *} \\ 0.8 & <1\end{array}$

$* p<: 8 \delta_{1}$ 
Table 3

ANOVA on the Number of CRs Emitted During Days 1 and 2 of Tone Acquisition

\begin{tabular}{lrrr} 
SV & DF & MS & F \\
\hline Lesion Type (L) & 2 & 2,232 & $<1$ \\
S/L & 12 & $5,383.9$ & \\
Blocks (B) & 9 & $9,095.4$ & $23.83 *$ \\
B x L & 18 & 406.8 & 1.06 \\
SB/L & 108 & 381.6 & \\
\hline p & &
\end{tabular}

Table 4

ANOVA on the Number of CRs Emitted During Days 1 and 2 of Light Plus Tone Acquisition

\begin{tabular}{lrrr} 
SV & DF & \multicolumn{1}{c}{ MS } & $F$ \\
\hline Lesion Type (L) & 2 & $7,413.2$ & 2.21 \\
S/L & 12 & $3,354.8$ & \\
Blocks (B) & 9 & $11,120.3$ & $20.48 *$ \\
B x L & 18 & 714.8 & 1.32 \\
SB/L & 108 & 543.0 & \\
\hline
\end{tabular}

Table 5

ANOVA on the Number of CRs Emitted to Tone During the Test Phase

SV

DF

MS

F

$\begin{array}{cccc}\text { Lesion Type (L) } & 2 & 502.4 & 1.02 \\ \text { Sit Vs Block (T) } & 1 & 2,920.5 & 5.91 * \\ \text { L X T } & 2 & 405 & <1 \\ \text { S/LT } & 24 & 493.9 & \end{array}$

${ }^{*} p<.025$ 
Appendix D

Results of the Statistical Analysis Performed in Experiment 2 
Table 1

ANOVA on the Differentiation Scores

\begin{tabular}{lrrl} 
SV & DF & \multicolumn{1}{c}{ MS } & \multicolumn{1}{l}{ S } \\
\hline Lesion Type (L) & 2 & $1,603.3$ & $<1$ \\
S/L & 24 & $7,481.6$ & \\
CS+ VS CS- (T) & 1 & $117,481.5$ & $29.06 *$ \\
L T T & 2 & 62.3 & $<1$ \\
ST/L & 24 & $4,042.9$ & \\
Days (D) & 14 & $26,811.4$ & $35.01^{*}$ \\
L X D & 28 & 419.4 & $<1$ \\
SD/L & 336 & 765.8 & \\
T X D & 14 & $2,195.6$ & $12.58 *$ \\
L T T D & 28 & 163.2 & $<1$ \\
STD/L & 336 & 174.5 & \\
& & &
\end{tabular}

p $<.001$

Table 2

ANOVA on the Percentage of CRs Emitted During Retardation SV Testing

Lesion Type (L)

S/L

Days (D)

$D \times L$

$\mathrm{SD} / \mathrm{L}$

DF MS F

2
24
2
4
48

$$
\begin{array}{r}
163.2 \\
1,178.2 \\
24,647.8 \\
1,314.3 \\
1,300.7
\end{array}
$$

< 1

18. $95^{*}$

1.01

$\mathrm{p}<.001$

\section{Table 3}

ANOVA on the Number of Trials to Reach 5 Consecutive CRs

$\begin{array}{lrrr}\text { SV } & \text { DF } & \text { MS } & \text { F } \\ \begin{array}{l}\text { Lesion Type (L) } \\ \text { S/L }\end{array} & 2 & 165.4 & <1 \\ & 24 & 4,560.6 & \end{array}$

Table 4

ANOVA On the Number of Trials to Reach 10 Consecutive CRS

\begin{tabular}{lrrr} 
SV & DF & MS & \multicolumn{1}{l}{ M } \\
\hline Lesion Type (L) & 2 & 255.2 & $<1$ \\
S/L & 24 & $5,396.0$ & \\
\hline
\end{tabular}



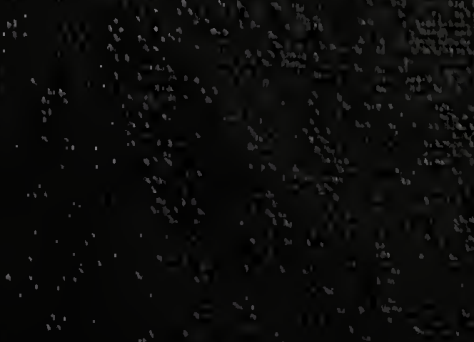